\title{
Signaling through CD5 Activates a Pathway Involving Phosphatidylinositol 3-Kinase, Vav, and Rac1 in Human Mature T Lymphocytes
}

\author{
SONJA I. GRINGHUIS, ${ }^{1,2}$ LOU F. M. H. DE LEIJ, ${ }^{2}$ PAUL J. COFFER, ${ }^{3}$ AND EDO VELLENGA ${ }^{1 *}$ \\ Divisions of Hematology ${ }^{1}$ and Clinical Immunology, ${ }^{2}$ Department of Internal Medicine, \\ University of Groningen, 9713 GZ Groningen, and Department of Pulmonary \\ Diseases, University Hospital Utrecht, 3584 CX Utrecht,$^{3}$ The Netherlands
}

Received 28 July 1997/Returned for modification 29 September 1997/Accepted 1 December 1997

\begin{abstract}
CD5 acts as a coreceptor on $\mathrm{T}$ lymphocytes and plays an important role in T-cell signaling and T-cell-B-cell interactions. Costimulation of $\mathrm{T}$ lymphocytes with anti-CD5 antibodies results in an increase of the intracellular $\mathrm{Ca}^{2+}$ levels, and subsequently in the activation of $\mathrm{Ca}^{2+} /$ calmodulin-dependent (CaM) kinase type IV. In the present study, we have characterized the initial signaling pathway induced by anti-CD5 costimulation. The activation of phosphatidylinositol (PI) 3-kinase through tyrosine phosphorylation of its p85 subunit is a proximal event in the CD5-signaling pathway and leads to the activation of the lipid kinase activity of the p110 subunit. The PI 3-kinase inhibitors wortmannin and LY294002 inhibit the CD5-induced response as assessed in interleukin-2 (IL-2) secretion experiments. The expression of an inactivated Rac1 mutant (Rac1 • N17) in T lymphocytes transfected with an IL-2 promoter-driven reporter construct also abrogates the response to CD5 costimulation, while the expression of a constitutively active Rac1 mutant (Rac1-V12) completely replaces the CD5 costimulatory signal. The Rac1-specific guanine nucleotide exchange factor Vav is heavily phosphorylated on tyrosine residues upon CD5 costimulation, which is a prerequisite for its activation. A role for Vav in the CD5-induced signaling pathway is further supported by the findings that the expression of a dominant negative Vav mutant (Vav-C) completely abolishes the response to CD5 costimulation while the expression of a constitutively active Vav mutant $[\operatorname{Vav}(\Delta 1-65)]$ makes the CD5 costimulation signal superfluous. Wortmannin is unable to block the $\operatorname{Vav}(\Delta 1-65)$ - or Rac1 $\cdot$ V12-induced signals, indicating that both Vav and Rac1 function downstream from PI 3-kinase. Vav and Rac1 both act upstream from the CD5-induced activation of CaM kinase IV, since KN-62, an inhibitor of CaM kinases, and a dominant negative CaM kinase IV mutant block the $\operatorname{Vav}(\Delta 1-65)$-and Rac1 $\cdot$ V12-mediated signals. We propose a model for the CD5-induced signaling pathway in which the PI 3-kinase lipid products, together with tyrosine phosphorylation, activate Vav, resulting in the activation of Rac1 by the Vav-mediated exchange of GDP for GTP.
\end{abstract}

The CD5 receptor, which is expressed on the surface of all $\mathrm{T}$ lymphocytes as well as on a subset of B lymphocytes, is a 67-kDa monomeric transmembrane glycoprotein that belongs to the scavenger receptor cysteine-rich family of extracellular domain-like structures $(1,11,28)$. The counterreceptor of CD5 has been identified as CD72, a dimeric receptor which is commonly expressed on B lymphocytes (63). A second ligand of CD5, termed CD5L, is present on activated splenic B lymphocytes (4). In view of its involvement in the interactions between $\mathrm{T}$ and $\mathrm{B}$ lymphocytes and also between different subsets of B lymphocytes, it has been proposed that CD5 plays an important role in the regulation of the immune response $(4,11,13$, $44,57)$.

The CD5 receptor on T lymphocytes is associated with the T-cell receptor (TCR)-CD3-CD4 (or CD8) complex, which also comprises the protein tyrosine kinases $\mathrm{p} 56^{\text {lck }}$ and $\mathrm{p} 59^{f y n}$, and it depends on this physical association for its functional activity $(3,8,30,40,54)$. Once the TCR-CD3 complex is engaged by ligand, the cytoplasmic domain of CD5 becomes rapidly phosphorylated on tyrosine residues, as are the TCR $\zeta$ chains $(8,17,44)$. These tyrosines are present in a potential tyrosine kinase phosphorylation motif $\left(\mathrm{Y}^{-\mathrm{X}_{11}}-\mathrm{Y}-\mathrm{XX}\right)$, which is

* Corresponding author. Mailing address: Division of Hematology, University of Groningen, Hanzeplein 1, 9713 GZ Groningen, The Netherlands. Phone: 3150361 2933. Fax: 3150361 4862. E-mail: e .vellenga@int.azg.nl. similar to the immunoreceptor tyrosine activation motifs as found in the TCR $\zeta$ and CD3 chains $(3,44)$. Once the tyrosine residues in this motif became phosphorylated, they can serve as docking sites for SH2 (Src homology 2) domain-containing proteins $(44,53)$. The protein tyrosine kinase $\mathrm{p} 56^{\text {lck }}$, which is associated with CD4 or CD8 (50), seems to be responsible for the phosphorylation of the tyrosine residues in the cytoplasmic domain of the CD5 receptor upon TCR engagement. It has also been demonstrated that $\mathrm{p} 56^{\text {lck }}$ binds to the cytoplasmic domain of CD5 through its $\mathrm{SH} 2$ domain and becomes fully activated once bound, probably through autophosphorylation (44).

The costimulation of $\mathrm{T}$ lymphocytes via the CD5 receptor augments the intracellular calcium and cyclic GMP levels (30, 35 ). Subsequently, both interleukin-2 (IL-2) secretion and IL-2 receptor expression are enhanced $(1,12,23,30)$. Recently, we reported that costimulation of $\mathrm{T}$ lymphocytes with anti-CD5 antibodies results in the activation of the $\mathrm{Ca}^{2+} /$ calmodulindependent kinase type IV (CaM kinase IV) (23). The lymphoid cell- and brain-specific CaM kinase IV is activated through phosphorylation on threonine-196 by CaM kinase kinase, which in turn is activated by an increase of the intracellular $\mathrm{Ca}^{2+}$ levels $(41,51,59,60)$. The enhanced activation of CaM kinase IV through CD5 costimulation is associated with an increase of the AP-1 activity at the IL-2 promoter, resulting in an enhanced transcription and expression of the IL-2 gene (23). The mitogen-activated protein kinases, ERK (extracellu- 
lar signal-regulated kinase), JNK (c-Jun N-terminal kinase), and $\mathrm{p3} / \mathrm{Mpk} 2$, which play an important role in the activation of AP-1 through a multitude of extracellular stimuli $(10,61)$, are not activated by the CD5-induced signaling pathway (23).

In the present study, we set out to elucidate the signaling pathways induced by CD5 costimulation and to identify the potential $\mathrm{SH} 2$ domain-containing proteins which initiate the CD5 signal transduction route. We present evidence that phosphatidylinositol 3-kinase (PI 3-kinase) is activated by ligation of the CD5 receptor and that PI 3-kinase activates Rac1 through a mechanism involving the guanine exchange factor Vav. Most significantly, we found that the activation of both Vav and Rac1 is indispensable for the CD5-induced signaling pathway.

\section{MATERIALS AND METHODS}

T-lymphocyte isolation. Human peripheral blood cells were obtained from healthy volunteer platelet donors, and mononuclear cell suspensions were prepared by Ficoll-Hypaque (Lymphoprep; Nycomed, Oslo, Norway) density gradient centrifugation. T lymphocytes were isolated by 2 -aminoethylisothiouronium bromide-treated sheep erythrocyte rosetting. The sheep erythrocytes were lysed with $155 \mathrm{mM} \mathrm{NH} 4 \mathrm{Cl}-10 \mathrm{mM} \mathrm{KHCO}{ }_{3}-0.1 \mathrm{mM}$ EDTA by standard procedures. The remaining cell preparations contained more than $98 \%$ T lymphocytes as assessed by flow cytometric analysis after being stained with an anti-CD2 monoclonal antibody (MAb) (Becton Dickinson, Mountain View, Calif.) and less than 1\% CD14-positive cells (Becton Dickinson). After isolation, T lymphocytes were kept overnight at $37^{\circ} \mathrm{C}$ in RPMI 1640 medium (BioWhittaker, Verviers, Belgium) containing $2 \%$ fetal calf serum (FCS; HyClone, Logan, Utah) supplemented with $2 \mathrm{mM}$ L-glutamine, $100 \mathrm{U}$ of penicillin per $\mathrm{ml}, 100 \mu \mathrm{g}$ of streptomycin per $\mathrm{ml}$, and $6 \mathrm{ng}$ of colistin per $\mathrm{ml}$

Stimulation. Human T lymphocytes $\left(5 \times 10^{6} / \mathrm{ml}\right)$ were incubated for various periods with $2 \mu \mathrm{g}$ of phytohemagglutinin (PHA; Sigma, St. Louis, Mo.) per ml in combination with a MAb against CD28 (a gift from R. van Lier, Central Laboratory of the Netherlands Red Cross Blood Transfusion Service, Amsterdam, The Netherlands), used at a final concentration of $5 \%$ hybridoma culture supernatant, and/or a MAb against CD5 (83-P2E6; MCA Development, Groningen, The Netherlands), also used at 5\% hybridoma culture supernatant. Various inhibitors were added 30 to 60 min before stimulation: wortmannin (Sigma), an inhibitor of PI 3-kinase, was used at a final concentration of $100 \mathrm{nM}$; LY294002 [2-(4-morpholinyl)-8-phenyl-4H-1-benxopyran-4-one; AleXis Corp., Läufelfingen, Switzerland], also an inhibitor of PI 3-kinase, was used at a final concentration of $1 \mu \mathrm{M}$; rapamycin (AleXis), which inhibits the activation of p70 S6 kinase, was used at a final concentration of $20 \mathrm{ng} / \mathrm{ml}$; and $\mathrm{KN}-62$ [1-(N,O-bis(5-isoquinoline-sulfonyl)- $N$-methyl-L-tyrosyl)-4-phenyl-piperazine; AleXis], an inhibitor of $\mathrm{CaM}$ kinases, was used at a final concentration of $10 \mu \mathrm{M}$

Measurement of secreted IL-2 protein. Human T lymphocytes $\left(3 \times 10^{6} / \mathrm{ml}\right)$ were stimulated for $24 \mathrm{~h}$ with PHA plus anti-CD28 in the presence or absence of anti-CD5. Inhibitors were added $30 \mathrm{~min}$ before stimulation. Secreted IL-2 protein was quantified in cell-free supernatants with a human IL-2 enzyme-linked immunosorbent assay (ELISA) kit (R\&D Systems, Minneapolis, Minn.) as recommended by the manufacturer.

PKB and p70 S6K kinase activity assay. Total-cell lysates were prepared from stimulated human $\mathrm{T}$ lymphocytes after $10 \mathrm{~min}$ of stimulation for measurement of kinase activity. The T lymphocytes used for protein kinase B (PKB) assays were cultured in RPMI 1640 medium supplemented with $2 \mathrm{mM}$ L-glutamine and antibiotics, containing only $0.2 \%$ FCS. T lymphocytes $\left(5 \times 10^{7}\right)$ were left unstimulated or stimulated with PHA and anti-CD28 in the presence or absence of anti-CD5. The cells were harvested, washed once with phosphate-buffered saline (PBS), resuspended in $400 \mu \mathrm{l}$ of lysis buffer (20 mM HEPES [pH 7.4], $2 \mathrm{mM}$ EGTA, $1 \mathrm{mM}$ dithiothreitol [DTT], 1\% Triton X-100, 10\% glycerol) supplemented with protease inhibitors $(10 \mu \mathrm{g}$ of leupeptin [Sigma] per ml, $10 \mu \mathrm{g}$ of aprotinin [Sigma] per $\mathrm{ml}, 0.4 \mathrm{mM}$ phenylmethylsulfonyl fluoride [Sigma]) and phosphatase inhibitors ( $50 \mathrm{mM} \beta$-glycerophosphate, $1 \mathrm{mM} \mathrm{Na}_{3} \mathrm{VO}_{4}$ ), and incubated on ice for $20 \mathrm{~min}$. Insoluble debris was collected by centrifugation at $1,000 \times g$ for $10 \mathrm{~min}$ by $4^{\circ} \mathrm{C}$. The protein concentration of the cell lysates was determined by the Bradford assay (5).

$\mathrm{PKB}$ and p70 S6K were immunoprecipitated from $800 \mu \mathrm{g}$ of cell lysate by incubating it with an anti-PKB polyclonal antibody (PAb) (7) or an anti-p70 S6K PAb (sc-230; Santa Cruz Biotechnology, Santa Cruz, Calif.), respectively, for $1 \mathrm{~h}$ at $4^{\circ} \mathrm{C}$ with rotation and an additional $18 \mathrm{~h}$ after the addition of $20 \mu \mathrm{l}$ of protein G plus agarose beads (50\% slurry; Santa Cruz Biotechnology). The immunoprecipitates were divided in half: one part was used to confirm the equal precipitation of proteins, and the other part was used for the kinase assay as described below. For the detection of PKB and p70 S6K, the immunoprecipitates were centrifuged in a microcentrifuge for $30 \mathrm{~s}$ at $4^{\circ} \mathrm{C}$, washed twice times with PBS, and then boiled in $1 \times$ sodium dodecyl sulfate-polyacrylamide gel electrophoresis (SDS-PAGE) sample buffer. The proteins were separated by SDS-PAGE on a $12.5 \%$ gel, with Rainbow colored protein molecular weight markers (Amersham,
Little Chalfont, United Kingdom) as a reference, and transferred onto a polyvinylidene difluoride (PVDF; Millipore, Bedford, Mass.) membrane. The membrane was blocked for $1 \mathrm{~h}$ in PBS containing 5\% skin milk and $0.01 \%$ Tween 20 . $\mathrm{PKB}$ and p70 S6K were detected by incubating the membranes with anti-PKB PAb (1:1,000 dilution) or anti-p70 S6K PAb $(1: 1,000)$ for $1 \mathrm{~h}$ and then with a secondary antibody, swine anti-rabbit immunoglobulin-horseradish peroxidase (Ig-HRP) (1:5,000; Dako, Glostrup, Denmark), for $1 \mathrm{~h}$. The membranes were then assayed with the enhanced chemiluminescence (ECL) detection system (Amersham).

For the kinase assays, the immunoprecipitates were centrifuged in a microcentrifuge for $20 \mathrm{~s}$ at $4^{\circ} \mathrm{C}$, washed three times with lysis buffer, three times with $\mathrm{LiCl}$ buffer $(500 \mathrm{mM} \mathrm{LiCl}, 100 \mathrm{mM}$ Tris-HCl [pH 7.6], $1 \mathrm{mM}$ DTT, $0.1 \%$ Triton $\mathrm{X}-100)$, and finally three times with assay buffer $(50 \mathrm{mM}$ Tris- $\mathrm{HCl}$ [pH 7.6], 10 $\mathrm{mM} \mathrm{MgCl}, 1 \mathrm{mM}$ DTT, $0.1 \%$ Triton X-100 [for PKB]; $50 \mathrm{mM}$ morpholinepropanesulfonic acid [MOPS; [pH 7.2], $5 \mathrm{mM} \mathrm{MgCl}_{2}, 1 \mathrm{mM}$ DTT, $0.1 \%$ Triton $\mathrm{X}-100$ [for p70 S6K]). The PKB immunoprecipitates were assayed for kinase activity in $30 \mu \mathrm{l}$ of assay mix containing $50 \mathrm{mM}$ Tris- $\mathrm{HCl}(\mathrm{pH} 7.6), 10 \mathrm{mM} \mathrm{MgCl}$, $1 \mathrm{mM}$ DTT, 0.1\% Triton X-100, $2 \mu \mathrm{M}$ PKI (Santa Cruz Biotechnology), $30 \mu \mathrm{M}$ ATP, and $5 \mu \mathrm{Ci}$ of $\left[\gamma^{-32} \mathrm{P}\right] \mathrm{ATP}(3,000 \mathrm{Ci} / \mathrm{mmol}$; Amersham $)$ in a 20 -min assay at $30^{\circ} \mathrm{C}$, with $10 \mu \mathrm{g}$ of histone $2 \mathrm{~B}$ (Boehringer, Mannheim, Germany) as the substrate. The p70 S6K immunoprecipitates were assayed for kinase activity in 30

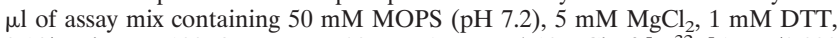
$0.1 \%$ Triton X-100, $2 \mu \mathrm{M}$ PKI, $30 \mu \mathrm{M}$ ATP, and $10 \mu \mathrm{Ci}$ of $\left[\gamma^{-32} \mathrm{P}\right] \mathrm{ATP}(3,000$ $\mathrm{Ci} / \mathrm{mmol}$; Amersham) in a 20 -min assay at $30^{\circ} \mathrm{C}$, with $15 \mu \mathrm{g}$ of $\mathrm{S} 6$ peptide (sc-3009; Santa Cruz Biotechnology) as the substrate. The reactions were terminated by the addition of $5 \times$ SDS-PAGE sample buffer and boiling. The proteins were separated by SDS-PAGE on a $15 \%$ gel, with Rainbow colored protein molecular weight markers as a reference. Phosphorylated substrates were quantitated with a PhosphorImaging system and the ImageQuant software (Molecular Dynamics, Sunnyvale, Calif.)

Plasmids. The ClaI-HindIII fragment of pIL2CAT (a gift from C. L. Verweij, Department of Rheumatology, Academic Hospital Leiden, Leiden, The Netherlands) containing the IL-2 promoter from positions -319 to +47 (64) was subcloned in the SmaI site of the pCAT3-enhancer reporter plasmid (Promega Corp., Madison, Wis.) to construct the reporter plasmid pCAT3e-IL2(-319/ $+47)$. The empty pCAT3-enhancer plasmid and the pCAT3-control reporter plasmid (Promega) served as negative and positive controls, respectively, in the transfection assays.

The expression plasmids used have been described previously. $\mathrm{pSR} \alpha-\Delta \mathrm{p} 85$ encodes a deletion mutant of the p85 subunit of PI 3-kinase (26). pEXV-mycRac1N17, encoding a myc-tagged dominant negative mutant of Rac1, pEXVmyc-Rac1V12, encoding a myc-tagged constitutively active mutant of Rac1, and pEXV-myc-Cdc42 2 N17, encoding a myc-tagged dominant negative mutant of Cdc42, were provided by A. Hall, CRC Oncogene and Signal Transduction Group, Department of Biochemistry, University College London, London, United Kingdom $(14,49)$. pGBT-RhoN19, encoding a dominant inhibitory mutant of Rho, was provided by M. Symons, ONYX Pharmaceuticals, Richmond, Calif., and was subcloned in the pCS2 + expression vector by R. van Weeghel, Department of Genetics, University of Groningen, Haren, The Netherlands (14). pME18S-dn CaMKIV, encoding a dominant negative mutant of CaM kinase IV, was kindly provided by T. R. Soderling, Vollum Institute, Oregon Health Sciences University, Portland, Oreg. (23). pEF-myc-Vav-C, encoding a myc-tagged dominant negative form of Vav, was provided by A. Weiss, Howard Hughes Medical Institute, Department of Medicine, University of California, San Francisco, Calif. (71). pMEX-Vav( $\Delta 1-65)$, encoding the constitutively active oncoprotein Vav, was provided by X. R. Bustelo, Department of Pathology, University Hospital and School of Medicine, State University of New York, Stony Brook, N.Y., with kind permission of M. Barbacid, Department of Molecular Biology, Bristol-Myers Squibb Pharmaceutical Research Institute, Princeton, N.J. (15).

Transfection. Resting primary $\mathrm{T}$ cells are refractory to conventional transfection methods; therefore, it was necessary to use a prestimulation method (42). Purified human T lymphocytes were cultured in RPMI 1640 medium containing $10 \%$ FCS, $2 \mathrm{mM}$ L-glutamine, and antibiotics, supplemented with PHA at 1 $\mu \mathrm{g} / \mathrm{ml}$ and recombinant human IL-2 (Cetus, Emeryville, Calif.) at $100 \mathrm{U} / \mathrm{ml}$. After 2 days of culture, the nonadherent cells were harvested, washed once with PBS, and resuspended in RPMI 1640 medium containing $10 \%$ FCS, 2 mM L-glutamine, and antibiotics, supplemented with only recombinant human IL-2 at $100 \mathrm{U} / \mathrm{ml}$. The $\mathrm{T}$ cells were incubated for a further 2 days, washed twice with PBS, and used for transient-transfection assays. A total of $15 \times 10^{6} \mathrm{~T}$ lymphocytes were resuspended in $400 \mu \mathrm{l}$ of RPMI 1640 medium containing $10 \%$ FCS, $2 \mathrm{mM}$ L-glutamine, antibiotics, and $100 \mathrm{U}$ of IL-2 per ml, and $15 \mu \mathrm{g}$ of reporter plasmid DNA plus $15 \mu \mathrm{g}$ of expression plasmid DNA were added. After a 10-min incubation on ice, the cells were electroporated with a gene pulser (Bio-Rad Laboratories, Richmond, Calif.) at $400 \mathrm{~V}$ and $960 \mu \mathrm{F}$. After an additional 5-min incubation period on ice, the cells were transferred to RPMI 1640 medium containing $10 \%$ FCS, 2 mM L-glutamine, antibiotics, and $100 \mathrm{U}$ of IL-2 per ml. At $1 \mathrm{~h}$ after electroporation, the cells were either left unstimulated or stimulated with PHA plus anti-CD28 in the presence or absence of anti-CD5. Inhibitors were added $1 \mathrm{~h}$ after the electroporation and $30 \mathrm{~min}$ before the stimulation. After $24 \mathrm{~h}$, the cells were harvested and resuspended in $150 \mu \mathrm{l}$ of $250 \mathrm{mM}$ 
Tris- $\mathrm{HCl}(\mathrm{pH}$ 7.8). Total-cell extracts were prepared by five repeated freeze-thaw cycles.

CAT ELISA. Chloramphenicol acetyltransferase (CAT) concentrations in total-cell extracts were measured with the CAT ELISA kit (Boehringer Mannheim) as recommended by the manufacturer. The protein concentration in the cell extracts was determined by the Bradford assay (5), and the results of the CAT ELISA were normalized by calculating the CAT concentration per microgram of protein in the total-cell extract.

Immunoprecipitation, Western blotting, and immunodetection. T lymphocytes $\left(4 \times 10^{7}\right.$ cells $)$ were left unstimulated or stimulated for 5 min with PHA and anti-CD28 in the presence or absence of anti-CD5. The cells were harvested, washed twice with PBS, and lysed for $20 \mathrm{~min}$ on ice in $400 \mu \mathrm{l}$ of lysis buffer (20 mM HEPES [pH 7.4], 2 mM EGTA, 1 mM DTT, 1\% Triton X-100, 10\% glycerol) supplemented with protease inhibitors $(10 \mu \mathrm{g}$ of leupeptin [Sigma] per $\mathrm{ml}, 10 \mu \mathrm{g}$ of aprotinin [Sigma] per $\mathrm{ml}, 0.4 \mathrm{mM}$ phenylmethylsulfonyl fluoride [Sigma]) and phosphatase inhibitors $(50 \mathrm{mM} \beta$-glycerophosphate, $1 \mathrm{mM}$ $\mathrm{Na}_{3} \mathrm{VO}_{4}$ ). Insoluble debris was collected by centrifugation at $1,000 \times g$ for $10 \mathrm{~min}$ at $4^{\circ} \mathrm{C}$. The protein concentration of the cell lysates was determined by the Bradford assay (5)

To detect proteins associated with the CD5 receptor, $600 \mu \mathrm{g}$ of cell lysate was incubated with $4.5 \mu \mathrm{g}$ of anti-CD5 MAb (83-P2E6) for $1 \mathrm{~h}$ at $4^{\circ} \mathrm{C}$ with rotation and for an additional $18 \mathrm{~h}$ after the addition of $30 \mu \mathrm{l}$ of protein A-agarose beads (50\% slurry). The immunoprecipitates were divided into three equal parts, centrifuged in a microcentrifuge for $30 \mathrm{~s}$ at $4^{\circ} \mathrm{C}$, washed twice with PBS, and then boiled in $1 \times$ SDS-PAGE sample buffer. The proteins were separated by SDSPAGE on a $10 \%$ gel with Rainbow colored protein molecular weight markers as a reference, and transferred onto a PVDF membrane. The membrane was blocked for $1 \mathrm{~h}$ in PBS containing 5\% skin milk and $0.01 \%$ Tween 20. CD5, p85 (PI 3-kinase), and Vav were detected by incubating the membranes with antiCD5 MAb (50\% hybridoma culture supernatant), anti-p85 PAb (1:500; a kind gift from J. A. Maassen, Department of Medical Biochemistry, University of Leiden, Leiden, The Netherlands), and anti-Vav PAb (1:500; sc-132, Santa Cruz Biotechnology) for $1 \mathrm{~h}$ and then with secondary antibodies, goat anti-mouse Ig-HRP (1:5,000; Amersham) or swine anti-rabbit Ig-HRP $(1: 5,000)$ for $1 \mathrm{~h}$. The membranes were then assayed with the ECL detection system (Amersham).

To detect tyrosine phosphorylation of proteins, Vav and p85 (PI 3-kinase) were immunoprecipitated from $250 \mu \mathrm{g}$ of cell lysate by incubating it with, respectively, $800 \mathrm{ng}$ of anti-Vav PAb or $3 \mu \mathrm{l}$ of anti-p85 PAb for $1 \mathrm{~h}$ at $4^{\circ} \mathrm{C}$ with rotation and for an additional $18 \mathrm{~h}$ after the addition of $20 \mu \mathrm{l}$ of protein A-agarose beads (50\% slurry). The immunoprecipitates were centrifuged in a microcentrifuge for $30 \mathrm{~s}$ at $4^{\circ} \mathrm{C}$, washed twice with lysis buffer, and then boiled in $1 \times$ SDS-PAGE sample buffer. The proteins were separated by SDS-PAGE on a $12.5 \%$ gel, with Rainbow colored protein molecular weight markers as a reference, and transferred onto a PVDF membrane. The membrane was blocked for $1 \mathrm{~h}$ in PBS containing 5\% skin milk and $0.01 \%$ Tween 20. Phosphorylated tyrosines were detected by incubating the membranes with anti-P-Tyr (PY20)HRP (1:1,000; sc-508-HRP [Santa Cruz Biotechnology]) for $1 \mathrm{~h}$. The membranes were then assayed with the ECL detection system. To ensure equal loading of the proteins, the membranes were stripped of bound antibodies by being incubated for $30 \mathrm{~min}$ at $55^{\circ} \mathrm{C}$ in stripping buffer $(100 \mathrm{mM}$ 2-mercaptoethanol, $2 \%$ SDS, 62.5 $\mathrm{mM}$ Tris- $\mathrm{HCl}[\mathrm{pH} 6.7])$ and then being incubated with primary antibodies (antiVav PAb, 1:500; anti-p85 pAb, 1:500) for $1 \mathrm{~h}$ and then with secondary antibodies, swine anti-rabbit Ig-HRP $(1: 5,000)$, for $1 \mathrm{~h}$. The membrane was then assayed again with the ECL detection system.

Statistical analysis. Statistical analyses of the data were performed with the Student's $t$ test for paired observations. The statistical significance of the data was at $P<0.05$.

\section{RESULTS}

PI 3-kinase is involved in the CD5-induced signaling pathway. PI 3-kinase is involved in many signaling pathways activated by lymphocyte membrane receptors, e.g., T-cell receptor (TCR) (20), CD19 (68), CD28 (66), and IL-2R (48). PI 3-kinase couples to these receptors through the $\mathrm{SH} 2$ domains of the p85 subunit, which can bind several distinct tyrosine-containing motifs found in the cytoplasmic domains of the receptors (67). The cytoplasmic domain of the CD5 receptor also contains such a motif with two tyrosine residues ( $\left.\mathrm{Y}-\mathrm{X}_{11}-\mathrm{Y}-\mathrm{XX}\right)$ $(3,44)$. To investigate whether PI 3-kinase plays a role in the signaling pathway activated by CD5, we performed interleukin-2 (IL-2) secretion experiments with two PI 3-kinase specific inhibitors, wortmannin (39) and LY294002 (65). Costimulation of T lymphocytes with anti-CD5 antibodies enhanced the IL-2 secretion twofold compared with stimulation with PHA plus anti-CD28: 1,1381 $\pm 1,725$ versus $22,868 \pm 3,025$ pg of IL-2 per $\mathrm{ml}$ (mean \pm standard error of the mean [SEM]; $n=4 ; P=$
0.003). The addition of wortmannin had no effect on the PHAplus anti-CD28-induced IL-2 secretion: 10,399 $\pm 1,896 \mathrm{pg}$ of IL-2 per ml (mean \pm SEM; $n=4$ ) but completely abrogated the response to costimulation with anti-CD5 antibodies: $13,573 \pm 1,897$ pg of IL-2 per ml (mean \pm SEM; $n=4)$ (Fig. 1A). The addition of LY294002 to T lymphocytes stimulated with PHA plus anti-CD28 inhibited the IL- 2 secretion by $50 \%$ $(7,796 \pm 2,096$ versus $4,023 \pm 996 \mathrm{pg}$ of IL-2 per ml; mean \pm SEM; $n=4 ; P=0.027)$. Similar to wortmannin, the increase in the IL-2 secretion in response to CD5 costimulation of PHA- plus anti-CD28-stimulated T cells was completely abolished by the addition of LY294002: 20,408 $\pm 5,517 \mathrm{pg}$ of IL-2 per $\mathrm{ml}$ in the absence of LY294002 versus 4,310 $\pm 885 \mathrm{pg}$ of IL-2 per $\mathrm{ml}$ in its presence (mean \pm SEM; $n=4$ ) (Fig. $1 \mathrm{~B}$ ). This indicates that inhibition of the PI 3-kinase activity completely blocks the CD5 signaling pathway. In addition, we investigated whether the expression of a deletion mutant of the p85 subunit of PI 3-kinase, $\Delta$ p85 (26), could block the response of T cells to CD5 costimulation. T lymphocytes were cotransfected with an IL-2 promoter-driven CAT reporter construct together with an empty control expression plasmid or the $\Delta \mathrm{p} 85$ expression plasmid. Costimulation of transfected control $\mathrm{T}$ cells with anti-CD5 enhanced the PHA- plus anti-CD28-induced CAT expression $(1.8 \pm 0.04)$-fold (mean $\pm \mathrm{SEM} ; n=$ $12 ; P<0.001)$. The expression of the dominant negative $\mathrm{p} 85$ mutant inhibited $36 \% \pm 5 \%($ mean $\pm \mathrm{SEM} ; n=3 ; P=0.017)$ of the PHA- plus anti-CD28-induced CAT expression, while the upregulation of the IL-2 promoter activity in response to anti-CD5 was completely abrogated by the expression of $\Delta \mathrm{p} 85$ $(n=3)$ (Fig. 1C).

We also determined the phosphorylation of the p85 subunit of PI 3-kinase, since it has been reported that p85 becomes phosphorylated on tyrosine residues before the activation of the PI 3-kinase $(2,37)$. Western blotting with anti-phosphotyrosine antibodies after immunoprecipitation of the $\mathrm{p} 85$ subunit from unstimulated or stimulated cells showed that stimulation of T lymphocytes with PHA plus anti-CD28 induced the phosphorylation of p85 after only 5 min of stimulation. The subsequent costimulation of $\mathrm{T}$ lymphocytes through the CD5 receptor increased the phosphorylation status of p85 extensively (Fig. 2), which marks the significance of the PI 3-kinase activity for the CD5-induced signaling pathway.

The effects of PI 3-kinase are not mediated through PKB or p70 S6 kinase. The lipid products of PI 3-kinase act on multiple downstream effectors (reviewed in reference 58), including the serine/threonine kinase PKB (also known as Akt). PKB is directly activated by binding of PI 3,4-bisphosphate to its pleckstrin homology $(\mathrm{PH})$ domain. Binding of PI 3,4- $\mathrm{P}_{2}$ facilitates the dimerization of $\mathrm{PKB}$, which is supposedly the mechanism of activation $(21,22,33)$. To examine the involvement of $\mathrm{PKB}$ in the CD5-induced signaling pathway, we performed a PKB-specific kinase assay. PKB was immunoprecipitated from $\mathrm{T}$ lymphocytes that were left unstimulated or stimulated with either PHA plus anti-CD28 or PHA and anti-CD28 plus anti$\mathrm{CD} 5$, and the specific PKB kinase activity was determined by measuring the phosphorylation of its substrate, histone $2 \mathrm{~B}$ (H2B). We detected a basal kinase activity of PKB present in unstimulated $\mathrm{T}$ lymphocytes, which was enhanced $(1.5 \pm 0.1)$ fold (mean $\pm \mathrm{SEM} ; n=3 ; P=0.014$ ) in PHA- plus anti-CD28 stimulated $\mathrm{T}$ lymphocytes. Costimulation with anti-CD5 did not further increase this PKB kinase activity $(n=3)$ (Fig. 3), indicating that $\mathrm{PKB}$ plays no role in the CD5-induced signaling pathway.

A second target for downstream signaling through PI 3-kinase is $\mathrm{p} 70 \mathrm{~S} 6 \mathrm{~K}$. The immunosuppressive drug rapamycin impedes the activation of p70 S6K (6). To investigate the role of 

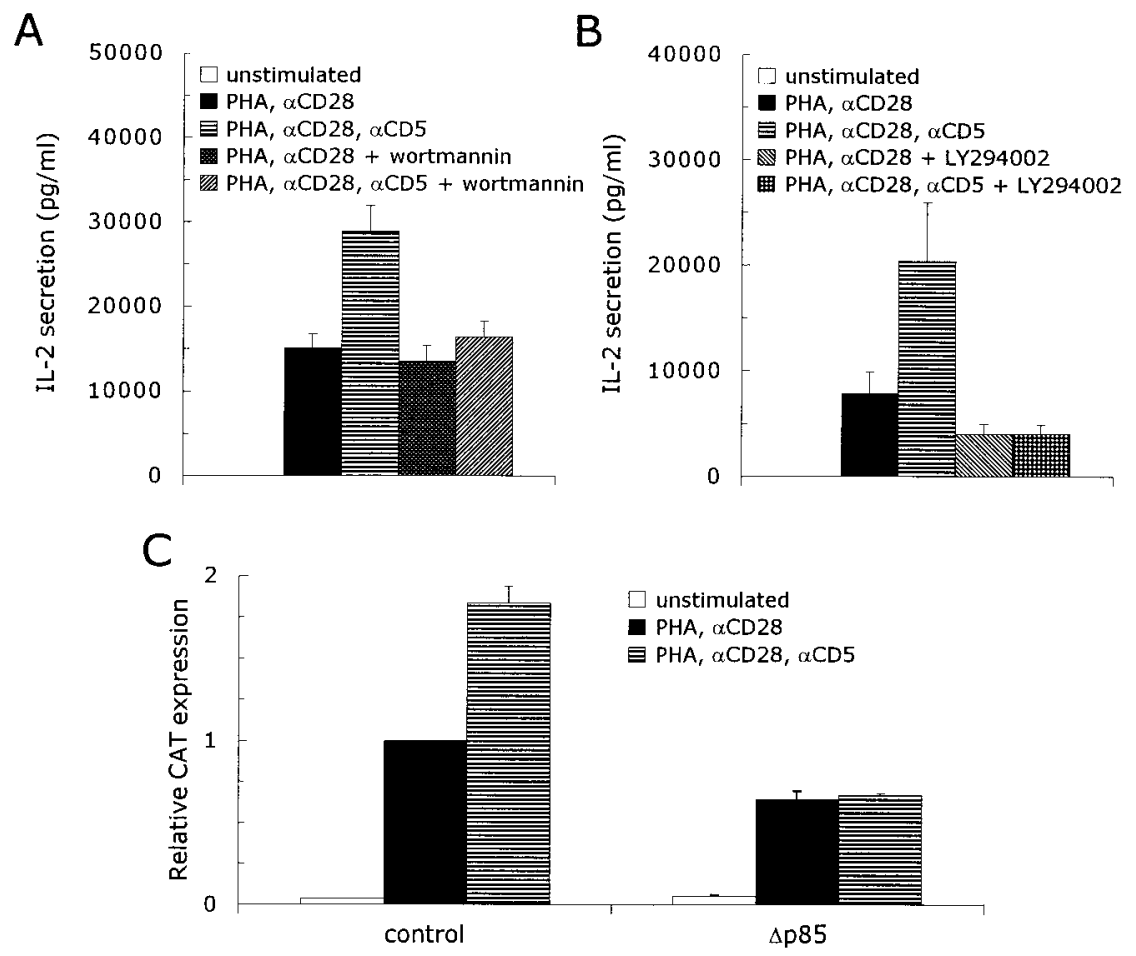

FIG. 1. Inhibition of the PI 3-kinase lipid kinase activity completely abrogates the CD5-induced upregulation of the IL-2 promoter activity in activated human T lymphocytes. (A and B) Human T lymphocytes were left unstimulated or stimulated with PHA plus anti-CD28 $(\alpha \mathrm{CD} 28) \pm$ anti-CD5 $(\alpha \mathrm{CD} 5)$ in the presence or absence of $100 \mathrm{nM}$ wortmannin (A) or $1 \mu \mathrm{M}$ LY294002 (B), both inhibitors of PI 3-kinase. Cell-free supernatants were harvested after $24 \mathrm{~h}$ and analyzed for secreted IL-2 protein. The mean values \pm SEMs for the IL-2 secretion observed in four independent experiments are shown. (C) Human T cells, prestimulated as described in Materials and Methods, were transfected with $15 \mu \mathrm{g}$ of pCAT3e-IL-2(-319/+47) together with $15 \mu \mathrm{g}$ of either an empty control expression plasmid (control) or the expression plasmid for a dominant negative p85 mutant $(\Delta \mathrm{p} 85)$. Transfected cells were left alone for $1 \mathrm{~h}$, divided into three groups, and subsequently left unstimulated or stimulated with PHA plus anti-CD28 $(\alpha \mathrm{CD} 28)$ or PHA plus anti-CD28 and anti-CD5 $(\alpha \mathrm{CD} 5)$ for $24 \mathrm{~h}$. CAT expression was measured as described in Materials and Methods. The results are expressed as the relative CAT expression compared to the PHA- plus anti-CD28-induced CAT expression in the transfected control T cells, which was set at 1 . The mean values \pm SEMs found for the relative CAT expression in three independent experiments are shown.

p70 S6K in the CD5-induced signaling pathway, we performed IL-2 secretion experiments with rapamycin. Costimulation of PHA- plus anti-CD28-stimulated T lymphocytes with anti-CD5 resulted in a 2.1-fold induction of the IL-2 secretion: 4,482 \pm 807 versus $9,575 \pm 1,526$ pg of IL- 2 per ml (mean \pm SEM; $n=$ 4; $P=0.007)$. In the presence of rapamycin, $\mathrm{T}$ lymphocytes stimulated with PHA plus anti-CD28 secreted $76 \% \pm 5 \%$ less IL-2: $1,067 \pm 232$ pg of IL-2 per ml (mean \pm SEM; $n=4 ; P=$ 0.047); however, costimulation with anti-CD5 subsequently enhanced the IL-2 secretion 2.4-fold to $2,523 \pm 679 \mathrm{pg}$ of IL-2 per ml (mean $\pm \mathrm{SEM} ; n=4 ; P=0.010$ ) (Fig. 4A). To determine whether CD5 costimulation modulates the activation of the p70 S6K kinase activity, we performed a specific kinase assay with the S6 peptide as a substrate. We detected a low basal kinase activity of p70 S6K present in unstimulated T lymphocytes. Stimulation of T lymphocytes with PHA plus anti-CD28 enhanced the p70 S6K kinase activity almost (5.4 土 0.12 )-fold (mean $\pm \mathrm{SEM} ; n=3 ; P=0.017$ ); however, costimulation with anti-CD5 did not further augment the p70 S6K kinase activity $(n=3)$ (Fig. 4B), indicating that p70 S6K plays no role in the CD5-induced signaling pathway.

Rac1 is indispensable for the CD5-induced signaling pathway. The activation of the small GTPase Rac1 has also been reported to be mediated through PI 3-kinase activity $(27,38$, 47). To determine the involvement of Rac1 in the CD5-induced signaling pathway, we used a dominant inhibitory mutant of Rac1 (Rac1 - N17), which is locked in the GDP-bound state and is unresponsive to guanine nucleotide exchange factors (49) in transfection studies. T lymphocytes were cotrans- fected with an IL-2 promoter-driven CAT reporter construct together with an empty control expression plasmid or the Rac1 - N17 expression plasmid. The CAT expression of PHAplus anti-CD28-stimulated $\mathrm{T}$ cells in the control group was

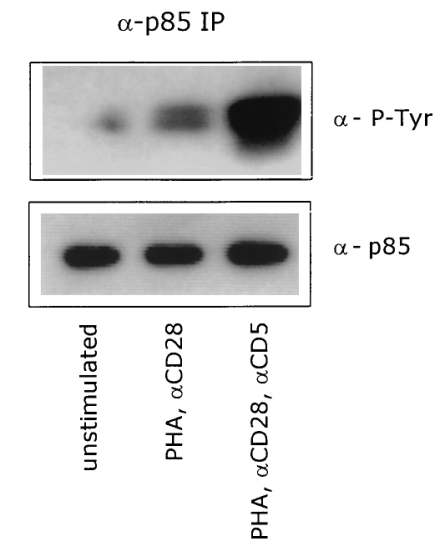

FIG. 2. CD5 costimulation enhances the tyrosine phosphorylation of the p85 subunit of PI 3-kinase. T cells were left unstimulated or stimulated with PHA plus anti-CD28 $(\alpha \mathrm{CD} 28)$ in the presence or absence of anti-CD5 $(\alpha \mathrm{CD} 5)$ for 5 min. p85 was immunoprecipitated from total-cell lysates, and tyrosine-phosphorylated $\mathrm{p} 85$ was detected with anti-PY20 MAb $(\alpha-\mathrm{P}$-Tyr) by ECL Western blotting as described in Materials and Methods. To ensure equal levels of immunoprecipitated p85, the blot was stripped and reprobed with anti-p85 PAb ( $\alpha-\mathrm{p} 85)$. The data are representative of three independent experiments. 

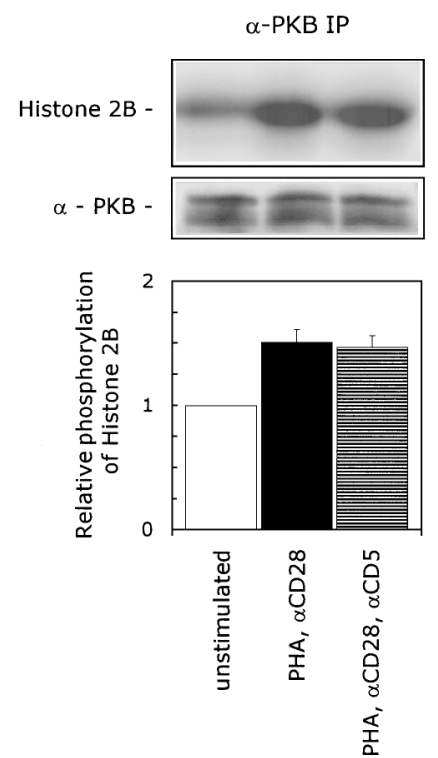

FIG. 3. CD5 signaling is independent of PKB activation. T cells were left unstimulated or stimulated with PHA plus anti-CD28 $(\alpha \mathrm{CD} 28)$ in the presence or absence of anti-CD5 ( $\alpha$ CD5) for $10 \mathrm{~min}$. The cells were lysed, and immunoprecipitated $\mathrm{PKB}$ was assayed for kinase activity, with $\mathrm{H} 2 \mathrm{~B}$ as a substrate. To ensure the equal precipitation of $\mathrm{PKB}$, the immunoprecipitates were loaded onto an SDS $-12.5 \%$ polyacrylamide gel, and PKB protein was detected by ECL Western blotting as described in Materials and Methods. The kinase assay shown is representative of three independent experiments. The specific PKB kinase activity is determined by quantification of phosphorylated $\mathrm{H} 2 \mathrm{~B}$ with a PhosphorImaging system. The lower graph shows the relative phosphorylation of H2B. The phosphorylation of $\mathrm{H} 2 \mathrm{~B}$ detected in unstimulated cells was set at 1 . The mean values \pm SEMs found in three independent experiments are shown.

$(1.8 \pm 0.04)$-fold (mean $\pm \mathrm{SEM} ; n=12 ; P<0.001)$ enhanced after costimulation with anti-CD5 (Fig. 5A). The expression of dominant negative Rac1 blocked $58 \% \pm 4 \%$ (mean \pm SEM; $n=6 ; P<0.001)$ of the PHA- plus anti-CD28 induced CAT expression, while the costimulatory effect of anti-CD5 was almost completely abolished by the expression of Rac1 - N17 $(n=6)$ (Fig. 5B). Therefore, the use of a dominant inhibitory Rac1 mutant shows that Rac1 plays a vital role in the CD5induced signaling pathway. Cotransfections with a constitutively active Rac1 mutant (Rac1 - V12) (49) confirmed the importance of Rac1 in the CD5 signal transduction route. The expression of Rac1 - V12 was sufficient to induce a CAT expression in PHA- plus anti-CD28-stimulated T lymphocytes that is comparable to the CAT expression induced in transfected control T cells stimulated with PHA plus anti-CD28 and anti-CD5. Subsequent costimulation of Rac1 - V12transfected, PHA- plus anti-CD28- stimulated T cells with anti-CD5 enhanced the CAT expression only slightly $(n=3$; $P=0.36$ ) (Fig. 5E). To establish whether the Rac1-related small GTPases Rho and Cdc42 are also involved in the CD5induced signaling pathway, we cotransfected $\mathrm{T}$ lymphocytes with the IL-2 promoter-driven CAT reporter construct together with expression plasmids for dominant negative mutants for Rho (Rho - N19) and Cdc42 (Cdc42 • N17) (14). Both Rho • N19 and Cdc42 - N17 blocked the PHA- plus anti-CD28 induced CAT expression partially with $28 \% \pm 5 \%$ (mean \pm SEM; $n=3 ; P=0.006$ ) (Fig. $5 \mathrm{C}$ ) and $35 \% \pm 4 \%$ (mean \pm SEM; $n=3 ; P=0.004$ ) (Fig. 5D), respectively. However, the expression of the dominant negative Rho and Cdc42 mutants did not impede the upregulation of the IL-2 promoter activity in response to CD5 costimulation: in the presence of Rho
N19, the PHA- plus anti-CD28-induced CAT expression was enhanced $(1.9 \pm 0.08)$-fold (mean $\pm \mathrm{SEM} ; n=3 ; P<0.001)$ (Fig. 5C), and in the presence of $\mathrm{Cdc} 42 \cdot \mathrm{N} 17$, the upregulation was $(1.9 \pm 0.12$ )-fold (mean $\pm \mathrm{SEM} ; n=3 ; P=0.009)$ (Fig. $5 \mathrm{D})$.

To assess the position of Rac1 in the CD5-induced signaling pathway, we first used the PI 3-kinase inhibitor wortmannin. Similar to the IL-2 secretion experiments (Fig. 1A), wortmannin had no effect on the PHA- plus anti-CD28-induced CAT expression in transfected control T lymphocytes but completely abolished the response to CD5 costimulation $(n=3 ; P=$ $0.010)$. In contrast, the expression of Rac1 - V12 made the transfected $\mathrm{T}$ cells insensitive to the inhibitory effects of wortmannin (Fig. 5F), indicating that the expression of constitutively active Rac1 can replace the PI 3-kinase-induced signaling pathway. We used the CaM kinase inhibitor $\mathrm{KN}-62$ to further pinpoint the position of Rac1 in the CD5 signaling pathway $(19,23)$. We have previously demonstrated that the CD5-induced elevation of the intracellular $\mathrm{Ca}^{2+}$ levels activates CaM kinase IV (23). KN-62 had no effect on the PHAplus anti-CD28-induced IL-2 promoter activity but completely abrogated the costimulatory effect of anti-CD5 $(n=3 ; P=$ 0.007). The addition of KN-62 to Rac1 - V12-transfected T lymphocytes reduced the CAT expression in both PHA- plus anti-CD28-stimulated and PHA- plus anti-CD28- plus antiCD5-stimulated $\mathrm{T}$ cells to a level comparable to that in transfected control $\mathrm{T}$ cells stimulated with PHA plus anti-CD28 $(n=3 ; P=0.044)$ (Fig. 5G). These results were confirmed by the coexpression of a dominant negative mutant of CaM kinase IV (23) together with the constitutively active Rac1 mutant. Similar to the experiments with KN-62, the dominant negative CaM kinase IV mutant completely blocked the effect of Rac1 •

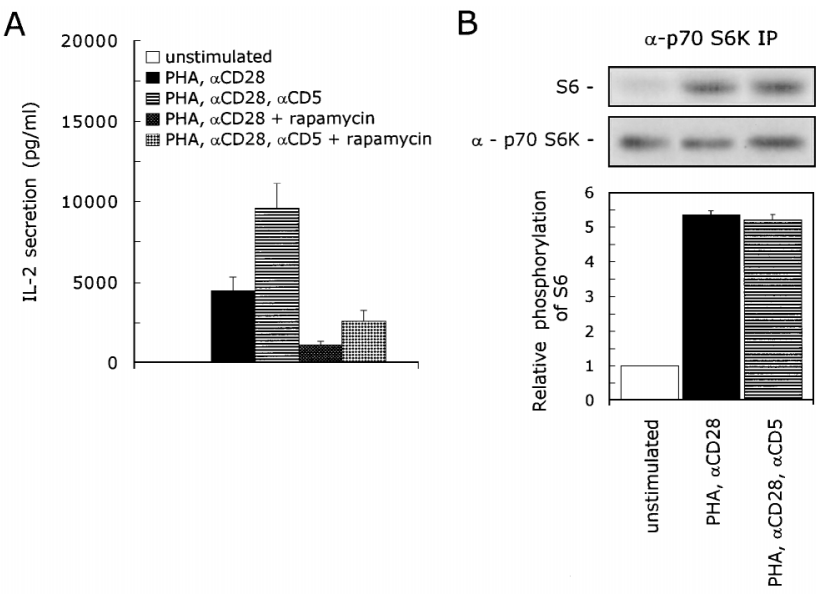

FIG. 4. CD5 signaling is independent of p70 S6K activation. (A) T cells were stimulated with PHA with or without anti-CD28 ( $\alpha$ CD28) and anti-CD5 $(\alpha$ CD5) in the presence or absence of $20 \mathrm{ng}$ of rapamycin per ml. Cell-free supernatants were harvested after $24 \mathrm{~h}$ and analyzed for secreted IL-2 protein. The mean values \pm SEM for the IL-2 secretion found in four independent experiments are shown. (B) T cells were left unstimulated or stimulated with PHA plus anti-CD28 $(\alpha \mathrm{CD} 28)$ in the presence or absence of anti-CD5 $(\alpha \mathrm{CD} 5)$ for $10 \mathrm{~min}$. The cells were lysed, and immunoprecipitated p 70 S6K was assayed for kinase activity with $\mathrm{S} 6$ peptide as a substrate. To ensure the equal precipitation of $\mathrm{p} 70 \mathrm{~S} 6 \mathrm{~K}$, the immunoprecipitates were loaded onto an SDS-12.5\% polyacrylamide gel, and p70 S6K protein was detected by ECL Western blotting as described in Materials and Methods. The kinase assay shown is representative of two independent experiments. The specific p70 S6K kinase activity is determined by quantification of phosphorylated S6 with a PhosphorImaging system. The lower graph shows the relative phosphorylation of S6. The phosphorylation of S6 detected in unstimulated cells was set at 1 . The mean values \pm SEMs found in two independent experiments are shown. 

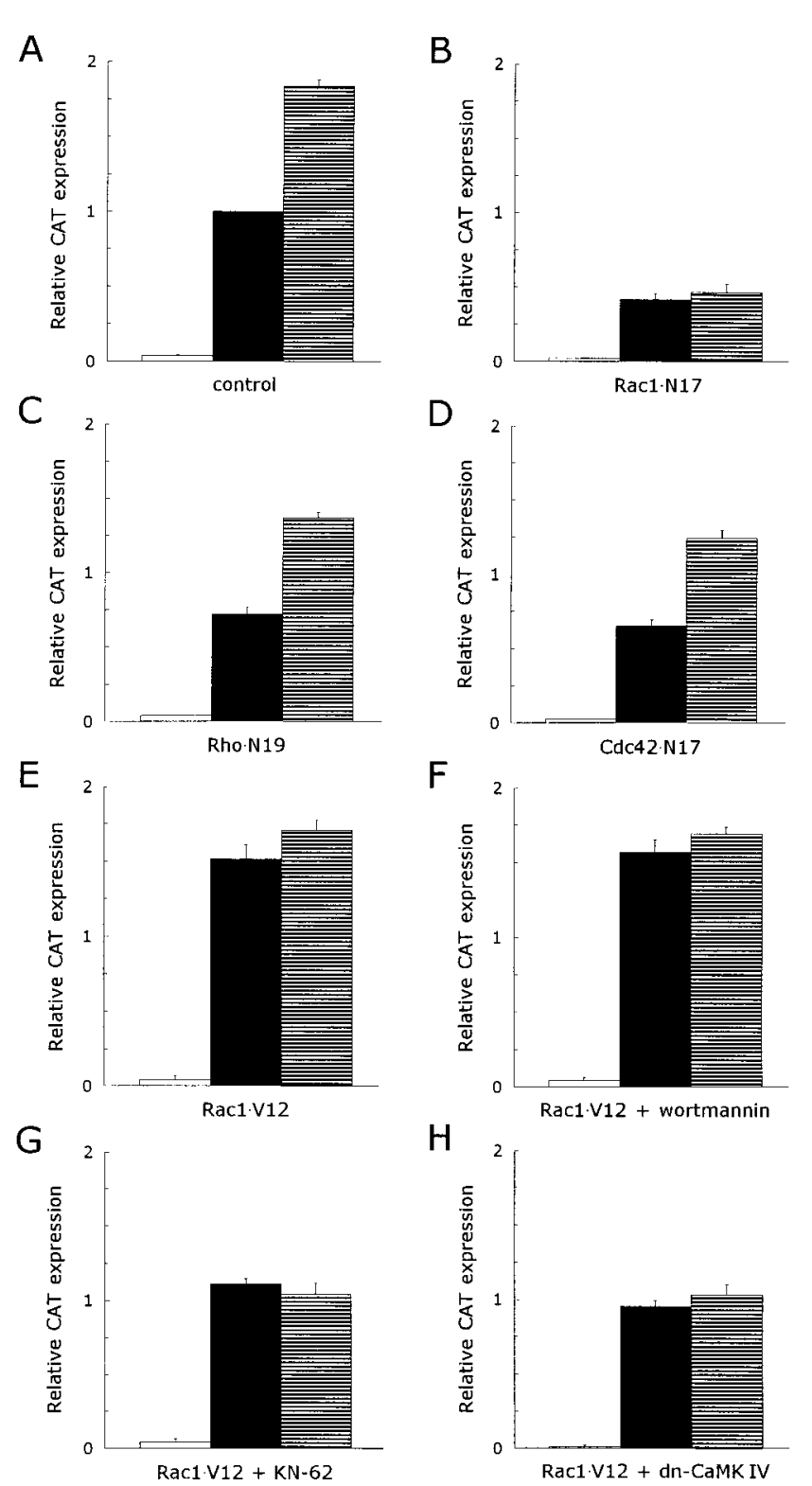

FIG. 5. Rac1 is essential to the CD5 costimulatory signal pathway leading to an upregulation of the IL-2 promoter activity, while Rho and Cdc42 play no role in this pathway. The CD5-induced signaling pathway in T lymphocytes expressing constitutively active Rac1 is insensitive to wortmannin but still sensitive to KN-62 or the expression of a dominant negative CaM kinase IV mutant. T cells, prestimulated as described in Materials and Methods, were transfected with 15 $\mu \mathrm{g}$ of pCAT3e-IL-2 $(-319 /+47)$ together with $15 \mu \mathrm{g}$ of either an empty control expression plasmid (control) (A) or the expression plasmid(s) for dominant negative or constitutively active mutants (B to $\mathrm{H}$ ): dominant negative Rac1 (Rac1 - N17) (B), dominant negative Rho (Rho - N19) (C), dominant negative Cdc42 (Cdc42 - N17) (D), constitutively active Rac1 (Rac1 • V12) (E to G), and constitutively active Rac1 (Rac1 $\cdot \mathrm{V} 12)$ in combination with dominant negative $\mathrm{CaM}$ kinase IV $(\mathrm{H})$. Transfected cells were left alone for $1 \mathrm{~h}$, divided into three groups, and subsequently left unstimulated $(\square)$ or stimulated with PHA plus anti-CD28 (ם) or PHA plus anti-CD28 and anti-CD5 (目) for $24 \mathrm{~h}$ in the presence of $100 \mathrm{nM}$ wortmannin (F) or $10 \mu \mathrm{M} \mathrm{KN}-62(\mathrm{G})$. CAT expression was measured as described in Materials and Methods. The results are expressed as the relative CAT expression compared to the PHA- plus anti-CD28-induced CAT expression in the transfected control T cells, which was set at 1 . The mean values \pm SEMs found for the relative CAT expression in three to six independent experiments are shown.
$\alpha$-Vav IP

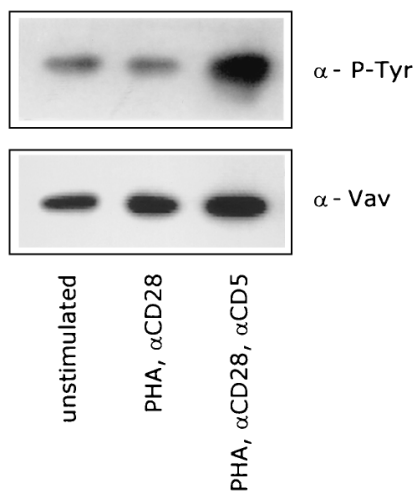

FIG. 6. CD5 costimulation enhances the tyrosine phosphorylation of the Rac1-specific GEF factor Vav. T cells were left unstimulated or stimulated with PHA plus anti-CD28 $(\alpha \mathrm{CD} 28)$ in the presence or absence of anti-CD5 ( $\alpha \mathrm{CD} 5)$ for $5 \mathrm{~min}$. Vav was immunoprecipitated from total-cell lysates, and tyrosinephosphorylated Vav was detected with anti-PY20 MAb ( $\alpha$-P-Tyr) by using ECL Western blotting as described in Materials and Methods. To ensure equal levels of immunoprecipitated Vav, the blot was stripped and reprobed with anti-Vav $\mathrm{pAb}(\alpha-\mathrm{p} 85)$. The data are representative of three independent experiments.

V12 on the IL-2 promoter activity $(n=3 ; P=0.036)$ (Fig. $5 \mathrm{H})$. These results indicate that Rac1 acts downstream of PI 3-kinase and upstream of the $\mathrm{Ca}^{2+}$-mediated activation of $\mathrm{CaM}$ kinase type IV in the CD5-induced signaling pathway.

The Rac1 guanine nucleotide exchange factor Vav is activated by the CD5-induced signaling pathway. Although the mechanisms by which D3 phosphoinositides signal to Rac1 are unclear, Toker and Cantley recently suggested that a PH domain-containing guanine nucleotide exchange factor (GEF) might be involved (58). Vav has been shown to be a Rac1/Rho family-specific GEF $(15,16,25,56)$, which is expressed exclusively in hematopoietic and trophoblast cells $(9,31,72)$. Vav contains an array of structural motifs, including a PH domain (36). Recent reports have shown that phosphorylation of Vav on tyrosine residues is required for its nucleotide exchange activity $(16,24,25,56,70)$. To determine whether Vav is phosphorylated upon stimulation of the CD5 receptor, we immunoprecipitated Vav from unstimulated or stimulated T cells and performed Western blotting experiments with a phosphotyrosine-specific antibody. We could detect tyrosine-phosphorylated Vav in unstimulated $\mathrm{T}$ lymphocytes, and the level of tyrosine phosphorylation was not increased upon stimulation of T cells with PHA and anti-CD28. However, Vav was extensively phosphorylated on tyrosine residues upon subsequent costimulation of the T lymphocytes with anti-CD5 (Fig. 6), indicating that the CD5-induced signaling pathway induces the activation of Vav. To verify that Vav plays a significant role in the CD5-induced signaling pathway, we used both a dominant inhibitory (Vav-C) mutant (71) and a constitutively active $[\operatorname{Vav}(\Delta 1-65)$, the Vav oncogene] mutant (15) of Vav in transfection studies. Costimulation of transfected control T lymphocytes with anti-CD5 enhanced the CAT expression (1.8 \pm 0.04 )-fold (mean $\pm \mathrm{SEM} ; n=12 ; P<0.001$ ) compared to that for PHA- plus anti-CD28-stimulated T lymphocytes (Fig. 7A). The expression of dominant negative Vav blocked $39 \% \pm 5 \%$ (mean \pm SEM; $n=3 ; P=0.016$ ) of the PHA- plus anti-CD28induced CAT expression in transfected T lymphocytes. Subsequent costimulation with anti-CD5 did not result in an enhancement of the CAT expression $(n=3)$ (Fig. 7B). The expression of Vav-C thus completely blocked the CD5-induced signaling pathway, indicating that Vav is essential for this path- 

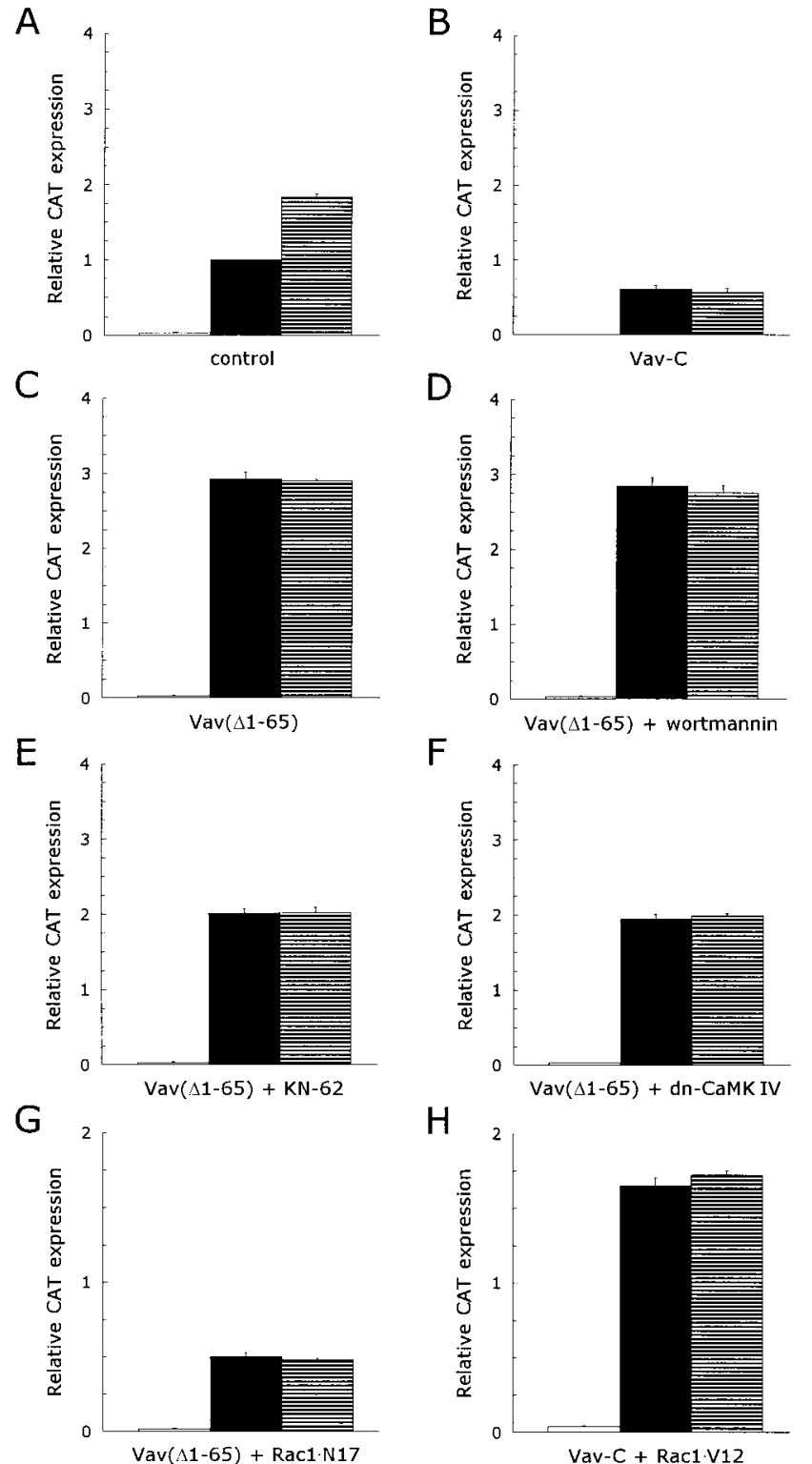

FIG. 7. Vav plays a major role in the CD5 signal pathway leading to an upregulation of the IL-2 promoter activity, as an upstream effector of Rac1. The signaling pathways in $\mathrm{T}$ lymphocytes expressing constitutively active Vav are insensitive to wortmannin but still sensitive to $\mathrm{KN}-62$ or the expression of a dominant negative CaM kinase IV mutant. T cells, prestimulated as described in Materials and Methods, were transfected with $15 \mu \mathrm{g}$ of pCAT3e-IL-2(-319/ +47 ) together with $15 \mu \mathrm{g}$ of either an empty control expression plasmid (control) (A) or the expression plasmid(s) for dominant negative or constitutively active mutants (B to H): dominant negative Vav (Vav-C) (B), constitutively active Vav $[\operatorname{Vav}(\Delta 1-65)](C$ to $E)$, constitutively active $\operatorname{Vav}[\operatorname{Vav}(\Delta 1-65)]$ in combination with dominant negative CaM kinase IV $(F)$, constitutively active $\operatorname{Vav}[\operatorname{Vav}(\Delta 1-$ 65)] in combination with dominant negative Rac1 (Rac1 - N17) (G), and constitutively active $\operatorname{Vav}[\operatorname{Vav}(\Delta 1-65)]$ in combination with constitutively active Rac1 (Rac1 - V12) (H). Transfected cells were left alone for $1 \mathrm{~h}$, divided into three groups, and subsequently left unstimulated $(\square)$ or stimulated with PHA plus anti-CD28 (ם) or PHA plus anti-CD28 and anti-CD5 (国) for $24 \mathrm{~h}$ in the presence of $100 \mathrm{nM}$ wortmannin (D) or $10 \mu \mathrm{M}$ KN-62 (E). CAT expression was measured as described in Materials and Methods. The results are expressed as the relative CAT expression compared to the PHA- plus anti-CD28-induced CAT expression in the transfected control T cells, which was set at 1 . The mean values \pm SEMs found for the relative CAT expression in three independent experiments are shown. way. The expression of the Vav oncogene, a constitutively active mutant, resulted in a strong increase in the CAT expression even when the transfected $\mathrm{T}$ cells were stimulated only with PHA plus anti-CD28: a (3.2 \pm 0.19$)$-fold (mean \pm SEM; $n=3 ; P=0.007)$ induction was observed compared to that for transfected control $\mathrm{T}$ cells stimulated with PHA plus antiCD28. The subsequent costimulation of $\operatorname{Vav}(\Delta 1-65)$-transfected, PHA- plus anti-CD28-stimulated T lymphocytes with anti-CD5 did not result in a further enhancement of the CAT expression $(n=3)$ (Fig. 7C), which implies that the CD5induced signaling pathway has been activated.

To establish the position of Vav in the CD5-induced signaling pathway, we performed cotransfection experiments with the IL-2 promoter-driven CAT reporter construct together with the constitutively active $\operatorname{Vav}$ oncogene, $\operatorname{Vav}(\Delta 1-65)$, in the presence of the PI 3-kinase inhibitor wortmannin. Wortmannin had no effect on the $\operatorname{Vav}(\Delta 1-65)$-induced CAT expression $(n=3)$ (Fig. 7D), indicating that PI 3-kinase is a upstream effector of Vav. Both the CaM kinase inhibitor KN-62 and the expression of a dominant negative CaM kinase IV mutant partially blocked the $\operatorname{Vav}(\Delta 1-65)$-induced CAT expression in transfected T cells stimulated with either PHA plus anti-CD28 or PHA plus anti-CD28 and anti-CD5: $31 \% \pm 2 \%$ (mean \pm SEM; $n=3 ; P=0.006$ ) (Fig. $7 \mathrm{E}$ ) and $34 \% \pm 2 \%$ (mean \pm SEM; $n=3 ; P<0.001$ ) (Fig. $7 \mathrm{~F}$ ), for $\mathrm{KN}-62$ and dominant negative CaM kinase IV, respectively. This result suggests that CaM kinase IV acts as a downstream effector in some signaling pathways mediated by Vav, including the CD5-induced signaling pathway.

Cotransfection experiments with constitutively active Vav and dominant negative Rac1 indicate that Rac1 acts downstream of Vav, since the CAT expression induced by either PHA plus anti-CD28 or PHA plus anti-CD28 and anti-CD5 stimulation was similar to that induced in Rac1 - N17-transfected T lymphocytes $(n=3)$ (Fig. 7G). In addition, the expression of dominant negative Vav did not inhibit the CAT expression induced by the expression of the constitutively active Rac1 mutant Rac1 - V12 in PHA- plus anti-CD28- or PHA- plus anti-CD28- plus anti-CD5-stimulated $\mathrm{T}$ lymphocytes $(n=3)$ (Fig. $7 \mathrm{H})$.

The p85 subunit of PI 3-kinase and Vav are associated with the CD5 receptor. It has been previously reported that Vav can associate with the p85 subunit of PI 3-kinase $(46,52,68)$. To determine whether this association is present at the cytoplasmic domain of the CD5 receptor, we performed Western blotting experiments after immunoprecipitating the CD5 receptor from either unstimulated or stimulated $\mathrm{T}$ lymphocytes. The CD5 receptor became associated with both p85 and Vav after a 5-min stimulation of the T cells with PHA plus anti-CD28, and this association remained unchanged after costimulation with anti-CD5 (Fig. 8).

\section{DISCUSSION}

CD5 acts as a coreceptor on $\mathrm{T}$ lymphocytes and plays an important role in T-cell signaling and T-cell-B-cell interactions through interactions with its counterreceptor CD72 on B lymphocytes $(1,4,13)$. Upon engagement of the TCR by ligand, the cytoplasmic domain of CD5 is phosphorylated on several tyrosine residues by $\mathrm{p} 56^{\text {lck }}$. It has also been demonstrated that p56 ${ }^{\text {lck }}$ can subsequently bind to the CD5 receptor through its SH2 domain and becomes fully activated through autophosphorylation $(18,44)$. It remains unknown what further signaling events take place once the CD5 receptor is stimulated, although it has been demonstrated that costimulation of $\mathrm{T}$ lymphocytes with anti-CD5 antibodies augments the intracel- 


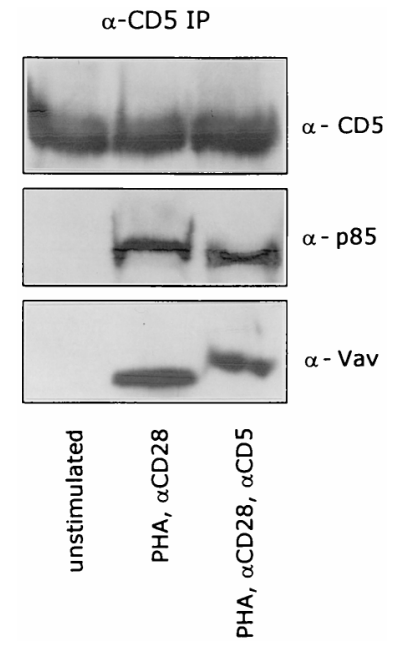

FIG. 8. The CD5 receptor is associated with p85 (PI 3-kinase) and Vav. T cells were left unstimulated or stimulated with PHA plus anti-CD28 $(\alpha \mathrm{CD} 28)$ in the presence or absence of anti-CD5 ( $\alpha$ CD5) for $5 \mathrm{~min}$. CD5 was immunoprecipitated from total-cell lysates, and CD5, p85, and Vav were detected by ECL Western blotting as described in Materials and Methods.

lular $\mathrm{Ca}^{2+}$ and cyclic GMP levels and activates the CaM kinase IV, which leads to the activation of the transcription factor AP-1 $(23,30,35)$. In this study, we have examined the initial signaling events, induced by ligation of the CD5 receptor, which are required for the elevation of the intracellular $\mathrm{Ca}^{2+}$ levels. We show that activation of PI 3-kinase is a proximal and essential step in the CD5 signaling pathway. The p85 subunit of PI 3-kinase is heavily phosphorylated on tyrosine residues within 5 min upon costimulation of T lymphocytes through the CD5 receptor. The phosphorylation of $\mathrm{p} 85$ is required to induce the lipid kinase activity of the p110 subunit $(2,37)$, although the protein tyrosine kinase responsible for this phosphorylation event has yet to be identified. Inhibition of the lipid kinase activity of PI 3-kinase with either wortmannin or LY294002 completely blocks the CD5 costimulatory signal, as assessed in IL-2 secretion experiments. Expression of a deletion mutant of p85, which lacks a binding site for the p110 subunit, also blocks the upregulation of the IL-2 promoter activity in response to CD5 costimulation. Recently, Dennehy et al. showed that the $\mathrm{SH} 2$ domains of the p85 subunit of PI 3-kinase can bind to the tyrosine-phosphorylated motifs in the cytoplasmic domain of the CD5 receptor in pervanadate-stimulated thymocytes (18), which supports our findings that activation of PI 3-kinase represents an early signaling event of the CD5 signaling pathway.

We demonstrate that the effects of PI 3-kinase activity in the CD5-induced signaling pathway are not mediated through the known downstream effectors PKB $(21,33)$ and p70 S6K (43). The kinase activity of PKB is not increased by costimulation of $T$ cells through the CD5 receptor. The activity of PKB is directly mediated by the binding of the PI 3-kinase lipid product PI 3,4-P $\mathrm{P}_{2}$ to its $\mathrm{PH}$ domain $(21,22,33)$, which implies that the activation of PI 3-kinase in response to CD5 ligation results in the generation of other D3 phosphoinositide products than PI 3,4- $\mathrm{P}_{2}$. The kinase activity of p70 S6K is also not affected by costimulation of $\mathrm{T}$ lymphocytes with anti-CD5. In addition, rapamycin, an inhibitor of p70 S6K activation, is unable to block the CD5-induced increase of the IL-2 secretion by PHAplus anti-CD28-stimulated T lymphocytes.

We show that the effects of PI 3-kinase are completely me- diated through the small GTPase Rac1 and not by the Rac1related GTPases Rho and Cdc42. The expression of a dominant inhibitory Rac1 mutant completely abolishes the response of transfected T cells to CD5 costimulation, while the expression of a constitutively active Rac1 mutant makes costimulation through CD5 superfluous. These results show that Rac1 is indispensable for the CD5-induced signaling pathway. The PI 3-kinase inhibitor wortmannin is unable to repress the CD5 signal in transfected $\mathrm{T}$ lymphocytes expressing constitutively active Rac1, indicating that Rac1 acts downstream from PI 3 -kinase; this is supported by studies from other groups $(27,38$, 47). Nobes et al. suggested that the production of PI 3,4,5- $\mathrm{P}_{3}$ by PI 3-kinase is required for the activation of Rac1 by plateletderived growth factor in NIH $3 \mathrm{~T} 3$ cells, resulting in actin polymerization at the plasma membrane (38). The regulation of signaling proteins through the D3 phosphoinositide products of PI 3-kinase are often mediated through PH domains. Individual $\mathrm{PH}$ domains have evolved specificity for PI 3,4- $\mathrm{P}_{2}$, PI $4,5-\mathrm{P}_{2}$ or PI 3,4,5- $\mathrm{P}_{3}(32,45,58)$. Rac1 contains no such $\mathrm{PH}$ domain. Toker and Cantley had already suggested that a $\mathrm{PH}$ domain containing GEF might be involved in the activation of Rac1 in response to increased cellular concentrations of D3 phosphoinositides (58). Vav is a Rac1-specific GEF and also contains a PH domain among several structural motifs $(16,36$, $56)$, suggesting that Vav is a potential candidate for the regulation of Rac1 through the lipid products of PI 3-kinase. Indeed, transfection experiments with dominant inhibitory and constitutively active Vav mutants confirm that Vav plays an essential role in the CD5-induced signaling pathway. Similar to the transfection experiments with the Rac1 mutants, we observe that dominant negative Vav completely abrogates the CD5 costimulatory response while constitutively active Vav fully activates the CD5 signaling pathway, making CD5 costimulation dispensable. Transfection experiments confirm that Vav is a downstream effector of PI 3-kinase and an upstream effector of Rac1. It is also shown that Vav becomes extensively phosphorylated on tyrosine residues upon CD5 costimulation, which is a prerequisite for activation of the exchange activity $(16,25,56)$. Vav can be phosphorylated by several protein tyrosine kinases, like p56 $6^{\text {lck }}(16,25)$, Syk (56), and Tyk2 (62). Since p56 lck associates with the CD5 receptor and subsequently becomes fully activated through autophosphorylation (44), it seems to be a major candidate for the CD5-induced tyrosine phosphorylation of Vav. Some reports suggest that Vav associates with the p85 subunit of PI 3-kinase $(42,52,68)$. The association between Vav and p85 might serve to recruit Vav to the multiprotein complex at the CD5 receptor, which brings it into close proximity with $\mathrm{p} 56^{\text {lck }}$, resulting in phosphorylation of Vav in response to CD5 costimulation. This is supported by the finding that both PI 3-kinase (p85) and Vav can be detected in anti-CD5 immunoprecipitates from stimulated T lymphocytes. The observation that both p85 and Vav associate with the CD5 receptor after T-cell receptor activation but are tyrosine phosphorylated only after CD5 receptor activation implies that CD5 stimulation is essential to induce the activity of a protein tyrosine kinase or to bring $\mathrm{p} 85$ and Vav in close proximity to an already activated protein tyrosine kinase, like p56 $6^{\text {lck }}$. Further experiments are necessary to fully understand the regulation of Vav through binding of D3 phosphoinositide products of PI 3-kinase to its PH domain and to identify the protein tyrosine kinases that are responsible for its phosphorylation upon ligation of the CD5 receptor.

The activation of both Vav and Rac1 precedes the activation of CaM kinase IV by the CD5 signaling pathway. The CaM kinase inhibitor $\mathrm{KN}-62$ and the expression of a dominant negative CaM kinase IV mutant are able to block the CD5 signal- 


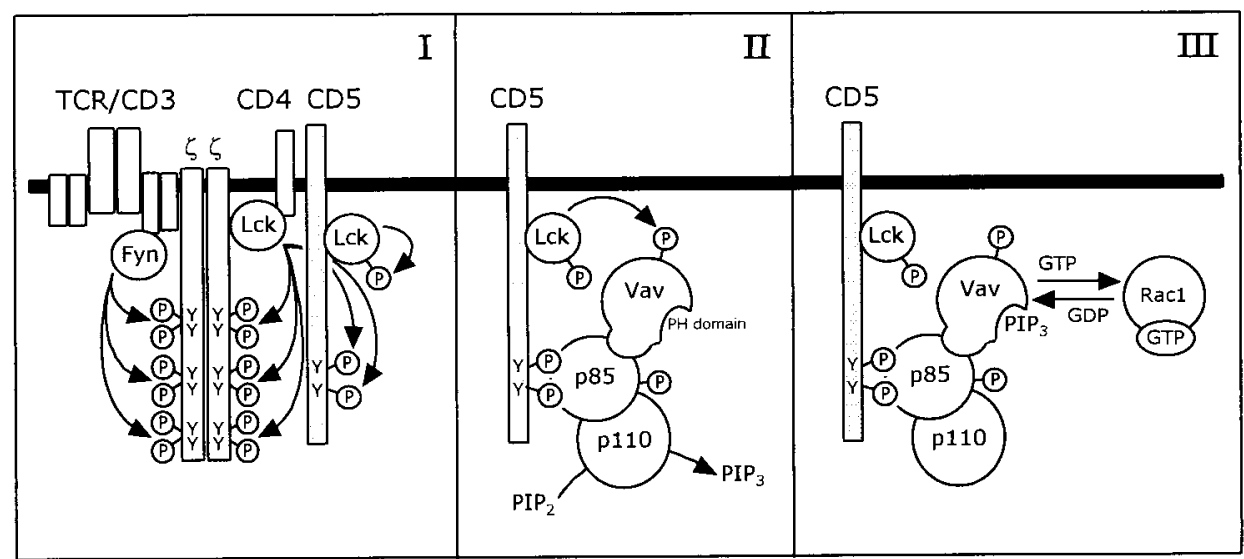

FIG. 9. Model for the CD5-induced signaling pathway, which is mediated by PI 3-kinase and Vav, resulting in the activation of Rac1. (I) Upon engagement of the TCR by ligand, the tyrosine residues in the cytoplasmic domain of the CD5 receptor are phosphorylated by the protein tyrosine kinase p56 $6^{l c k}$, as are the tyrosine residues in the $\zeta$ chains of the TCR-CD3 complex. p56 ck associates with the CD5 receptor and becomes fully activated through autophosphorylation. (II) The SH2 domains of the p85 subunit of PI 3-kinase bind to the phosphotyrosine residues of the CD5 receptor. Vav associates with the p85 subunit of PI 3-kinase, which serves to recruit Vav to the complex. Upon ligation of the CD5 receptor, PI 3-kinase is phosphorylated on tyrosine residues by a protein tyrosine kinase, most probably p56 activates the lipid kinase activity of the p110 subunit. The nucleotide exchange activity of Vav is preactivated through the phosphorylation of tyrosine residues, probably by $556^{c c k}$. (III) Upon binding of PI 3,4,5- $\mathrm{P}_{3}\left(\mathrm{PIP}_{3}\right)$ or another lipid product of PI 3-kinase to the PH domain of Vav, Vav becomes fully activated and will activate Rac1 through exchange of GDP for GTP.

ing pathway even in $\mathrm{T}$ cells that are transfected with the constitutively active Vav and Rac1 mutants. CaM kinase IV is directly activated by the CD5-induced elevations of the intracellular $\mathrm{Ca}^{2+}$ concentration (23), which implies that Rac1 is involved in the regulation of these elevations. The downstream effectors of Rac1 in the CD5-induced signaling pathway, possibly involved in the opening of membrane localized $\mathrm{Ca}^{2+}$ channels, remain elusive. It has previously been demonstrated that the downstream effectors of Rac1, JNK and p38/Mpk2, are not involved in the CD5-induced signaling pathway (23). These observations suggest that a signaling pathway, distinct from the mitogen-activated protein kinase cascades and probably more closely related to the pathways involved in the Rac1induced reorganization of the actin cytoskeleton $(29,34,38,49$, $55,69)$, is activated by Rac1 in response to CD5 costimulation of $\mathrm{T}$ lymphocytes. Further experiments are necessary to identify the downstream targets for Rac1 in the CD5 signaling pathway and to clarify how these effectors induce the observed $\mathrm{Ca}^{2+}$ influx.

Based on our results and the observations by other groups, we propose a model for the signaling pathway induced by CD5 costimulation, which is mediated through PI 3-kinase, Vav, and Rac1 (Fig. 9). Upon TCR engagement by ligand, the tyrosine residues in the cytoplasmic domain of the CD5 receptor are phosphorylated by $\mathrm{p} 56^{\text {lck }}$. p $56^{\text {lck }}$ associates with the CD5 receptor through its $\mathrm{SH} 2$ domain and becomes fully activated through autophosphorylation. The phosphorylated tyrosine residues serve as docking sites for the $\mathrm{SH} 2$ domains of the $\mathrm{p} 85$ subunit of PI 3-kinase. Vav associates with the p85 subunit of PI 3-kinase, which serves to recruit Vav to the complex at the CD5 receptor. It is conceivable that upon stimulation of the CD5 receptor, a conformational change of the cytoplasmic domain occurs, which brings both $\mathrm{p} 85$ and Vav in close proximity to a protein tyrosine kinase, most probably the CD5associated p56 lck. PI 3-kinase is subsequently phosphorylated on tyrosine residues, which indirectly activates the lipid kinase activity of the p110 subunit. Vav is also phosphorylated on tyrosine residues, which is necessary to activate its nucleotide exchange activity. The PI 3-kinase lipid product PI 3,4,5- $\mathrm{P}_{3}$, or another product, binds to the $\mathrm{PH}$ domain of Vav, which results in the full activation of Vav. Finally, Vav activates Rac1 by exchanging GDP for GTP, leaving Rac1 in the activated GTPbound state.

\section{ACKNOWLEDGMENTS}

We thank C. L. Verweij for providing pIL2CAT; A. Hall for providing $\mathrm{pEXV}$-Rac1 $\cdot \mathrm{N} 17$, pEXV-Rac1 $\cdot \mathrm{V} 12$, and $\mathrm{pEXV}-\mathrm{Cdc} 42 \cdot \mathrm{N} 17$; M. Symons for providing pGBT-Rho $\cdot$ N19; A. Weiss for providing pEF-myc-Vav-C; X. R. Bustelo and M. Barbacid for providing pMEX$\operatorname{Vav}(\Delta 1-65)$; and T. R. Soderling for his generous gift of pME18Sdominant negative CaM kinase IV. We also thank J. A. Maassen for his kind gift of anti-PI 3-kinase antiserum. We are grateful to A. E. Niemarkt for culturing the various hybridomas.

\section{REFERENCES}

1. Alberola-Ila, J., L. Places, D. A. Cantrell, J. Vives, and F. Lozano. 1992. Intracellular events involved in CD5-induced human T cell activation and proliferation. J. Immunol. 148:1287-1293.

2. al-Shami, A., S. G. Bourgoin, and P. H. Naccache. 1997. Granulocyte-macrophage colony-stimulating factor-activated signaling pathways in human neutrophils. I. Tyrosine phosphorylation-dependent stimulation of phosphatidylinositol 3-kinase and inhibition by phorbol esters. Blood 89:1035-1044.

3. Beyers, A. D., L. L. Spruyt, and A. F. Williams. 1992. Molecular associations between the T-lymphocyte antigen receptor complex and the surface antigens CD2, CD4, or CD8, and CD5. Proc. Natl. Acad. Sci. USA 89:29452949.

4. Biancone, L., M. A. Bowen, A. Lim, A. Aruffo, G. Andres, and L. Stamenkovic. 1996. Identification of a novel inducible cell-surface ligand of CD5 on activated lymphocytes. J. Exp. Med. 184:811-819.

5. Bradford, M. M. 1976. A rapid and sensitive method for the quantitation of microgram quantities of protein utilizing the principle of protein-dye binding. Anal. Biochem. 72:248-254.

6. Brown, E. J., M. W. Albers, T. B. Shin, K. Ichikawa, C. T. Keith, W. S. Lane, and S. L. Schreiber. 1994. A mammalian protein targeted by G1-arresting rapamycin-receptor complex. Nature 369:756-758.

7. Burgering, B. M. T., and P. J. Coffer. 1995. Protein kinase B (c-Akt) in phosphatidylinositol-3-OH kinase signal transduction. Nature 376:599-602.

8. Burgess, K. E., M. Yamamoto, K. V. S. Prasad, and C. E. Rudd. 1992. CD5 acts as a tyrosine kinase substrate within a receptor complex comprising T-cell receptor $\zeta$ chain/CD3 and protein-tyrosine kinases p56 $6^{\mathrm{lck}}$ and $\mathrm{p} 59^{\mathrm{fyn}}$. Proc. Natl. Acad. Sci. USA 89:9311-9315.

9. Bustelo, X. R., S. D. Rubin, K. L. Suen, D. Carrasco, and M. Barbacid. 1993. Developmental expression of the vav protooncogene. Cell Growth Differ. 4: 297-308.

10. Cahill, M. A., R. Janknecht, and A. Nordheim. 1996. Signalling pathways: Jack of all cascades. Curr. Biol. 6:16-19. 
11. Cerutti, A., L. Trentin, R. Zambello, R. Sancetta, A. Milani, C. Tassinari, F. Adami, C. Agostini, and G. Semenzato. 1996. The CD5/CD72 receptor system is coexpressed with several functionally relevant counterstructures on human B cells and delivers a critical signaling activity. J. Immunol. 157: 1854-1862.

12. Ceuppens, J. L., and M. L. Baroja. 1986. Monoclonal antibodies to the CD5 antigen can provide the necessary second signal for activation of isolated resting T cells by solid-phase-bound OKT3. J. Immunol. 137:1816-1821.

13. Clark, E. A., and J. A. Ledbetter. 1994. How B and T cells talk to each other. Nature 367:425-428.

14. Coso, O. A., M. Chiariello, J.-C. Yu, H. Teramoto, P. Crespo, N. Xu, T. Miki, and J. S. Gutkind. 1995. The small GTP-binding proteins Rac1 and Cdc42 regulate the activity of the JNK/SAPK signaling pathway. Cell 81:1137-1146.

15. Crespo, P., X. R. Bustelo, D. S. Aaronson, O. A. Coso, M. Lopez-Barahona, M. Barbacid, and J. S. Gutkind. 1996. Rac-1 dependent stimulation of the JNK/SAPK signaling pathway by Vav. Oncogene 13:455-460.

16. Crespo, P., K. E. Schuebel, A. A. Ostrom, J. S. Gutkind, and X. R. Bustelo. 1997. Phosphotyrosine-dependent activation of Rac-1 GDP/GTP exchange by the $v a v$ proto-oncogene product. Nature 385:169-172.

17. Davies, A. A., S. C. Ley, and M. J. Crumpton. 1992. CD5 is phosphorylated on tyrosine after stimulation of the T-cell antigen receptor complex. Proc. Natl. Acad. Sci. USA 89:6368-6372.

18. Dennehy, K. M., R. Broszeit, D. Garnett, G. A. Durrheim, L. L. Spruyt, and A. D. Beyers. 1997. Thymocyte activation induces the association of phosphatidylinositol 3-kinase and pp120 with CD5. Eur. J. Immunol. 27:679-686.

19. Enslen, H., P. Sun, D. Brickley, S. H. Soderling, E. Klamo, and T. R. Soderling. 1994. Characterization of $\mathrm{Ca}^{2+} /$ calmodulin-dependent protein kinase IV. Role in transcriptional regulation. J. Biol. Chem. 269:1552015527.

20. Exley, M., L. Varticovski, M. Peter, J. Sancho, and C. Terhorst. 1994. Association of phosphatidylinositol 3-kinase with a specific sequence of the $\mathrm{T}$ cell receptor $\zeta$ chain is dependent on T cell activation. J. Biol. Chem. 269: $15140-15146$.

21. Franke, T. F., D. R. Kaplan, L. C. Cantley, and A. Toker. 1997. Direct regulation of the Akt proto-oncogene product by phosphatidylinositol-3,4bisphosphate. Science 275:665-668.

22. Franke, T. F., D. R. Kaplan, and L. C. Cantley. 1997. PI3K: downstream AKTion blocks apoptosis. Cell 88:435-437.

23. Gringhuis, S. I., L. F. M. H. de Leij, G. A. Wayman, H. Tokumitsu, and E. Vellenga. 1997. The $\mathrm{Ca}^{2+}$ /calmodulin-dependent kinase type IV is involved in the CD5-mediated signaling pathway in human T lymphocytes. J. Biol. Chem. 272:31809-31820.

24. Gulbins, E., K. M. Coggeshall, G. Baier, S. Katzav, P. Burn, and A. Altman. 1993. Tyrosine kinase-stimulated guanine nucleotide exchange protein. Science 260:822-825.

25. Han, J., B. Das, W. Wei, L. van Aelst, R. D. Mosteller, R. Khosravi-Far, J. K. Westwick, C. J. Der, and D. Broek. 1997. Lck regulates Vav activation of members of the Rho family of GTPases. Mol. Cell. Biol. 17:1346-1353.

26. Hara, K., K. Yonezawa, H. Sakaue, A. Ando, K. Kotani, T. Kitamura, Y. Kitamura, H. Ueda, L. Stephens, T. R. Jackson, P. T. Hawkins, R. Dhand, A. E. Clark, G. D. Holman, M. D. Waterfield, and M. Kasuga. 1994. 1-Phosphatidylinositol 3-kinase activity is required for insulin-stimulated glucose transport but not for RAS activation in $\mathrm{CHO}$ cells. Proc. Natl. Acad. Sci. USA 91:7415-7419.

27. Hawkins, P. T., A. Eguinoa, R.-G. Qiu, D. Stokoe, F. T. Cooke, R. Walters, S. Wennström, L. Claesson-Welsh, T. Evans, M. Symons, and L. Stephens. 1995. PDGF stimulates an increase in GTP-Rac via activation of phosphoinositide 3-kinase. Curr. Biol. 5:393-403.

28. Jones, N. H., M. L. Clabby, D. P. Dialynas, H. J. S. Huang, L. A. Herzenberg, and J. L. Strominger. 1986. Isolation of complementary DNA clones encoding the human lymphocyte glycoprotein T1/Leu-1. Nature 323:346-349.

29. Joneson, T., M. McDonough, D. Bar-Sagi, and L. van Aelst. 1996. RAC regulation of actin polymerization and proliferation by a pathway distinct from Jun kinase. Science 274:1374-1376.

30. June, C. H., P. S. Rabinovitch, and J. A. Ledbetter. 1987. CD5 antibodies increase intracellular ionized calcium concentration in T cells. J. Immunol. 138:2782-2792.

31. Katzav, S., J. L. Cleveland, H. E. Heslop, and D. Pulido. 1991. Loss of the amino-terminal helix-loop-helix domain of the vav proto-oncogene activates its transforming potential. Mol. Cell. Biol. 11:1912-1920.

32. Klarlund, J. K., A. Guilherme, J. J. Holik, J. V. Virbasius, A. Chawla, and M. P. Czech. 1997. Signaling by phosphoinositide-3,4,5-trisphosphate through proteins containing pleckstrin and Sec7 homology domains. Science 275:1927-1930.

33. Klippel, A., W. M. Kavanaugh, D. Pot, and L. T. Williams. 1997. A specific product of phosphatidylinositol 3-kinase directly activates the protein kinase Akt through its pleckstrin homology domain. Mol. Cell. Biol. 17:338-344.

34. Lamarche, N., N. Tapon, L. Stowers, P. D. Burbelo, P. Aspenström, T. Bridges, J. Chant, and A. Hall. 1996. Rac and Cdc42 induce actin polymerization and G1 cell cycle progression independently of $\mathrm{p} 65^{\mathrm{PAK}}$ and the JNK/SAPK MAP kinase cascade. Cell 87:519-529.

35. Ledbetter, J. A., C. H. June, L. S. Grosmaire, and P. S. Rabinovitch. 1987.
Crosslinking of surface antigens causes mobilization of intracellular ionized calcium in T lymphocytes. Proc. Natl. Acad. Sci. USA 84:1384-1388.

36. Musacchio, A., T. Gibson, P. Rice, J. Thompson, and M. Saraste. 1993. The PH domain: a common piece in the structural patchwork of signalling proteins. Trends Biochem. Sci. 18:343-348.

37. Nave, B. T., R. J. Haigh, A. C. Hayward, K. Siddle, and P. R. Shepherd. 1996. Compartment specific regulation of phosphoinositide 3-kinase by plateletderived growth factor and insulin in 3T3-L1 adipocytes. Biochem. J. 318: $55-60$.

38. Nobes, C. D., P. Hawkins, L. Stephens, and A. Hall. 1995. Activation of the small GTP-binding proteins rho and rac by growth factor receptors. J. Cell Sci. 108:225-233.

39. Okada, T., L. Sakuma, Y. Fukui, O. Hazeki, and M. Ui. 1994. Blockage of chemotactic peptide-induced stimulation of neutrophils by wortmannin as a result of selective inhibition of phosphatidylinositol 3-kinase. J. Biol. Chem. 269:3563-3567.

40. Osman, N., S. C. Ley, and M. J. Crumpton. 1992. Evidence for an association between the $\mathrm{T}$ cell receptor/CD3 antigen complex and the CD5 antigen in human T lymphocytes. Eur. J. Immunol. 22:2995-3000.

41. Park, I.-K., and T. R. Soderling. 1995. Activation of $\mathrm{Ca}^{2+} /$ calmodulin-dependent protein kinase (CaM-kinase) IV by CaM-kinase kinase in Jurkat $\mathrm{T}$ lymphocytes. J. Biol. Chem. 270:30464-30469.

42. Park, J.-H., K. Kaushansky, and L. Levitt. 1993. Transcriptional regulation of interleukin 3 (IL3) in primary human T lymphocytes. Role of AP-1 and octamer-binding proteins in control of IL3 gene expression. J. Biol. Chem. 268:6299-6308.

43. Pullen, N., and G. Thomas. 1997. The modular phosphorylation and activation of $\mathrm{P} 70^{\mathrm{S} 6 \mathrm{~K}}$. FEBS Lett. 410:78-82.

44. Raab, M., M. Yamamoto, and C. E. Rudd. 1994. The T-cell antigen CD5 acts as a receptor and substrate for the protein-tyrosine kinase p56 $6^{\text {lck }}$. Mol. Cell. Biol. 14:2862-2870.

45. Rameh, L. E., A.-K. Arvidsson, K. L. Carraway III, A. D. Couvillon, G. Rathbun, A. Crompton, B. VanRenterghem, M. P. Czech, K. S. Ravichandran, S. J. Burakoff, D.-S. Wang, C.-S. Chen, and L. C. Cantley. 1997. A comparative analysis of the phosphoinositide binding specificity of pleckstrin homology domains. J. Biol. Chem. 272:22059-22066.

46. Ramos-Morales, F., B. J. Druker, and S. Fischer. 1994. Vav binds to several SH2/SH3 containing proteins in activated lymphocytes. Oncogene 9:19171923.

47. Reif, K., C. D. Nobes, G. Thomas, A. Hall, and D. A. Cantrell. 1996. PI 3-K signals activate a selective subset of Rac/Rho-dependent effector pathways. Curr. Biol. 6:1445-1455.

48. Reif, K., B. M. T. Burgering, and D. A. Cantrell. 1997. Phosphatidylinositol 3-kinase links the interleukin-2 receptor to protein kinase B and p70 S6 kinase. J. Biol. Chem. 272:14426-14433.

49. Ridley, A. J., H. F. Paterson, C. L. Johnston, D. Diekmann, and A. Hall. 1992. The small GTP-binding protein rac regulates growth factor-induced membrane ruffling. Cell 70:401-410.

50. Rudd, C. E., O. Janssen, K. V. S. Prasad, M. Raab, A. da Silva, J. C. Telfer, and M. Yamamoto. 1993. Src-related protein tyrosine kinases and their surface receptors. Biochim. Biophys. Acta 1155:239-266.

51. Selbert, M. A., K. A. Anderson, Q.-H. Huang, E. G. Goldstein, A. R. Means, and A. M. Edelman. 1995. Phosphorylation and activation of $\mathrm{Ca}^{2+}$-calmodulin-dependent protein kinase IV by $\mathrm{Ca}^{2+}$-calmodulin-dependent protein kinase Ia kinase. Phosphorylation of threonine 196 is essential for activation. J. Biol. Chem. 270:17616-17621.

52. Shigematsu, H., H. Iwasaki, T. Otsuka, Y. Ohno, F. Arima, and Y. Niho. 1997. Role of the vav proto-oncogene product (Vav) in erythropoietinmediated cell proliferation and phosphatidylinositol 3-kinase activity. J. Biol. Chem. 272:14334-14340.

53. Songyang, Z., S. E. Shoelson, M. Chaudhuri, G. Gish, T. Pawson, W. G. Haser, F. King, T. Roberts, S. Ratnofsky, R. J. Lechleider, B. G. Neel, R. B. Birge, J. E. Fajardo, M. M. Chou, H. Hanafusa, B. Schaffhausen, and L. C. Cantley. 1993. SH2 domains recognize specific phosphopeptide sequences. Cell 72:767-778.

54. Spertini, F., W. Stohl, N. Ramesh, C. Moody, and R. S. Geha. 1991. Induction of human $\mathrm{T}$ cell proliferation by a monoclonal antibody to CD5. J. Immunol. 146:47-52.

55. Tapon, N., and A. Hall. 1997. Rho, Rac and Cdc42 GTPases regulate the organization of the actin cytoskeleton. Curr. Opin. Cell Biol. 9:86-92.

56. Teramoto, H., P. Salem, K. C. Robbins, X. R. Bustelo, and J. S. Gutkind. 1997. Tyrosine phosphorylation of the vav proto-oncogene product links FceRI to the Rac1-JNK pathway. J. Biol. Chem. 272:10751-10755.

57. Thomas, Y., E. Glickman, J. DeMartino, J. Wang, G. Goldstein, and L. Chess. 1984. Biologic functions of the OKT1 T cell surface antigen. The T1 molecule is involved in helper function. J. Immunol. 133:724-730.

58. Toker, A., and L. C. Cantley. 1997. Signalling through the lipid products of phosphoinositide-3-OH kinase. Nature 387:673-676.

59. Tokumitsu, H., H. Enslen, and T. R. Soderling. 1995. Characterization of a $\mathrm{Ca}^{2+} /$ calmodulin-dependent protein kinase cascade. Molecular cloning and expression of calcium/calmodulin-dependent protein kinase kinase. J. Biol. Chem. 270:19320-19324. 
60. Tokumitsu, H., and T. R. Soderling. 1996. Requirements for calcium and calmodulin in the calmodulin kinase activation cascade. J. Biol. Chem. 271: $5617-5622$.

61. Treisman, R. 1996. Regulation of transcription by MAP kinase cascades. Curr. Opin. Cell Biol. 8:205-215.

62. Uddin, S., M. Sweet, O. R. Colamonici, J. J. Krolewski, and L. C. Platanias. 1997. The vav proto-oncogene product (p95vav) interacts with the Tyk-2 protein kinase. FEBS Lett. 403:31-34.

63. Van de Velde, H., H. Hoegen, W. Luo, J. R. Parnes, and K. Thielemans. 1991. The B-cell surface protein CD72/Lyb-2 is the ligand for CD5. Nature 351: $662-665$.

64. Verweij, C. L., M. Geerts, and L. A. Aarden. 1991. Activation of interleukin-2 gene transcription via the T-cell surface molecule CD228 is mediated through an NF-кB-like response element. J. Biol. Chem. 266:14179-14182.

65. Vlahos, C. J., W. F. Matter, K. Y. Hui, and R. F. Brown. 1994. A specific inhibitor of phosphatidylinositol 3-kinase, 2-(4-morpholinyl)-8-phenyl-4H-1benzopyran-4-one (LY294002). J. Biol. Chem. 269:5241-5248.

66. Ward, S. G., A. Wilson, L. Turner, J. Westwick, and D. M. Sansom. 1995. Inhibition of CD28-mediated $\mathrm{T}$ cell costimulation by the phosphoinositide 3-kinase inhibitor wortmannin. Eur. J. Immunol. 25:526-532.

67. Ward, S. G., C. H. June, and D. Olive. 1996. PI 3-kinase: a pivotal pathway in T-cell activation? Immunol Today 17:187-197.

68. Weng, W.-K., L. Jarvis, and T. W. LeBien. 1994. Signaling through CD19 activates Vav/Mitogen-activated protein kinase pathway and induces formation of a CD19/Vav/phosphatidylinositol 3-kinase complex in human B cell precursors. J. Biol. Chem. 269:32514-32521.

69. Westwick, J. K., Q. T. Lambert, G. J. Clark, M. Symons, L. van Aelst, R. G. Pestell, and C. J. Der. 1997. Rac regulation of transformation, gene expression, and actin organization by multiple, PAK-independent pathways. Mol. Cell. Biol. 17:1324-1335.

70. Wu, J., S. Katzav, and A. Weiss. 1995. A functional T-cell receptor signaling pathway is required for p95 vav activity. Mol. Cell. Biol. 15:4337-4346.

71. Wu, J., D. G. Motto, G. A. Koretzky, and A. Weiss. 1996. Vav and SLP-76 interact and functionally cooperate in IL-2 gene activation. Immunity 4: 593-602.

72. Zmuidzinas, A., K. Fischer, S. A. Lira, L. Forrester, S. Bryant, A. Bernstein, and M. Barbacid. 1995. The vav proto-oncogene is required early in embryogenesis but not for hematopoietic development in vitro. EMBO J. 14:1-11. 